\title{
Water Quality Projects Summary for the Mid- Columbia and Cumberland River Systems
}

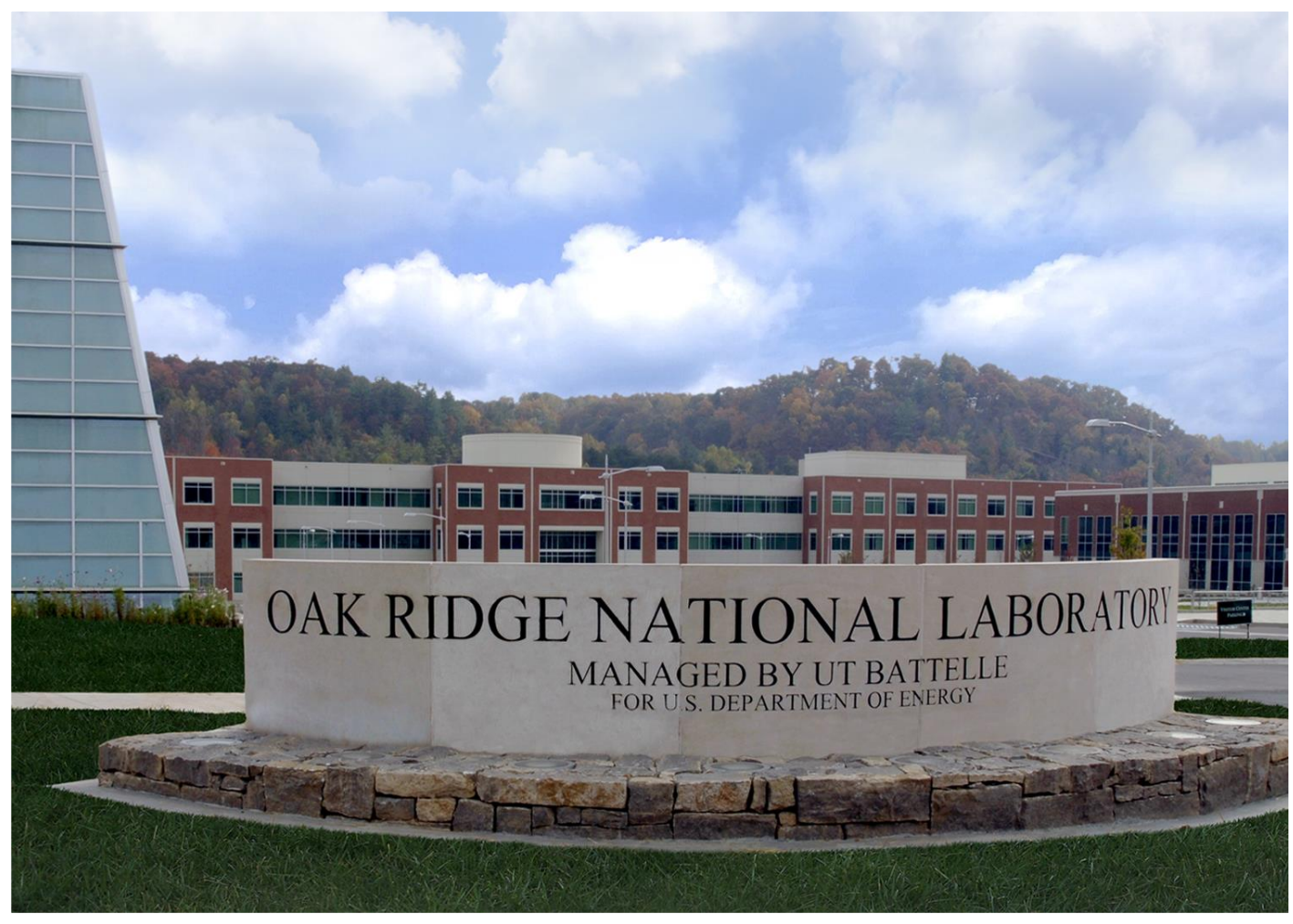

Approved for public release. Distribution is unlimited.
Kevin M. Stewart Adam Witt

Boualem Hadjerioua

September 2016 


\section{DOCUMENT AVAILABILITY}

Reports produced after January 1, 1996, are generally available free via US Department of Energy (DOE) SciTech Connect.

Website http://www.osti.gov/scitech/

Reports produced before January 1, 1996, may be purchased by members of the public from the following source:

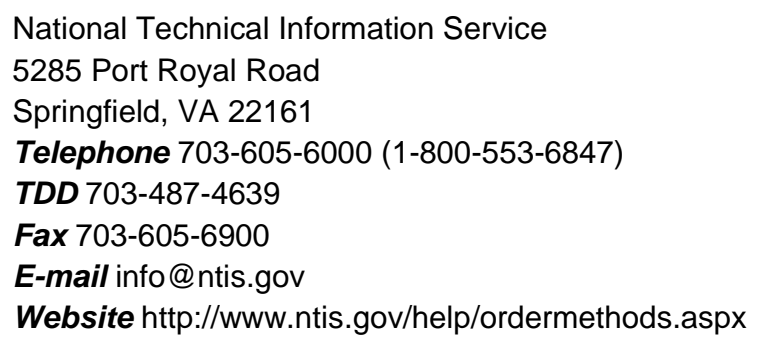

Reports are available to DOE employees, DOE contractors, Energy Technology Data Exchange representatives, and International Nuclear Information System representatives from the following source:

Office of Scientific and Technical Information

PO Box 62

Oak Ridge, TN 37831

Telephone 865-576-8401

Fax 865-576-5728

E-mail reports@osti.gov

Website http://www.osti.gov/contact.html

This report was prepared as an account of work sponsored by an agency of the United States Government. Neither the United States Government nor any agency thereof, nor any of their employees, makes any warranty, express or implied, or assumes any legal liability or responsibility for the accuracy, completeness, or usefulness of any information, apparatus, product, or process disclosed, or represents that its use would not infringe privately owned rights. Reference herein to any specific commercial product, process, or service by trade name, trademark, manufacturer, or otherwise, does not necessarily constitute or imply its endorsement, recommendation, or favoring by the United States Government or any agency thereof. The views and opinions of authors expressed herein do not necessarily state or reflect those of the United States Government or any agency thereof. 


\title{
Environmental Sciences Division
}

\section{WATER QUALITY PROJECTS SUMMARY FOR THE MID-COLUMBIA AND CUMBERLAND RIVER SYSTEMS}

\author{
Kevin M. Stewart \\ Adam Witt \\ Boualem Hadjerioua
}

Date Published: September 2016

\author{
Prepared for \\ U.S. Department of Energy \\ Wind and Water Program \\ Prepared by \\ OAK RIDGE NATIONAL LABORATORY \\ Oak Ridge, Tennessee 37831-6283 \\ Managed by \\ UT-BATTELLE, LLC \\ for the \\ US DEPARTMENT OF ENERGY \\ under contract DE-AC05-00OR22725
}




\section{TABLE OF CONTENTS}

Page

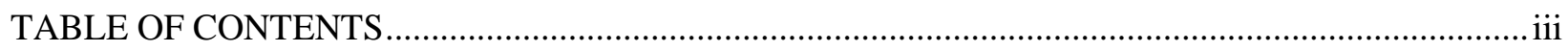

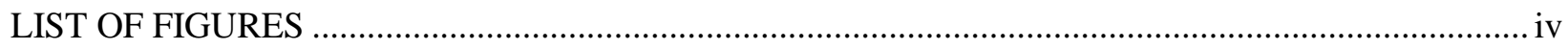

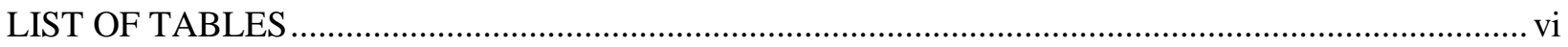

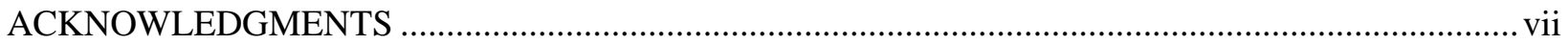

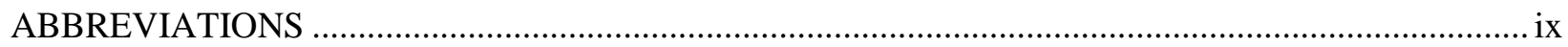

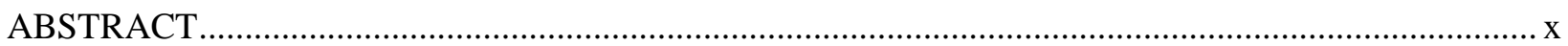

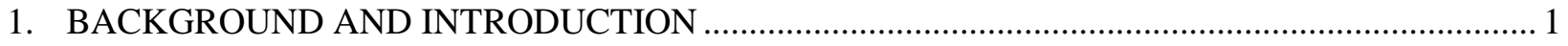

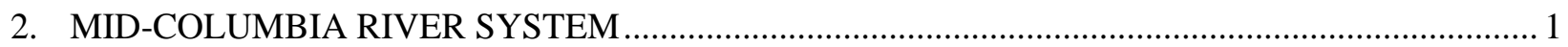

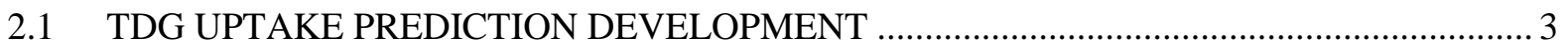

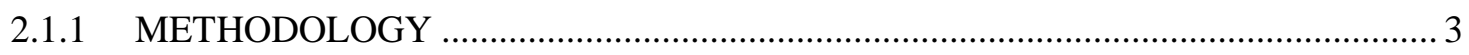

VALIDATION AND PERFORMANCE ............................................................. 4

2.1.2 4

2.2 IMPLEMENTATION OF TAILRACE TDG DEVELOPMENT INTO RIVERWARE ............ 6

2.2.1 OVERVIEW OF MID-COLUMBIA OPTIMIZATION MODEL .............................. 6

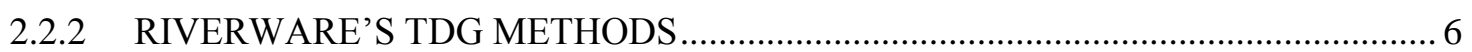

2.2.3 PRIEST RAPIDS TAILRACE TDG OPTIMIZATION ................................................. 6

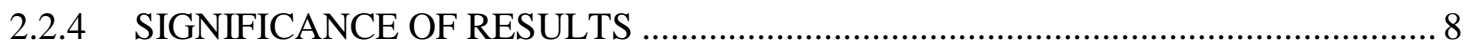

2.3 TDG TRANSFER PREDICTION ............................................................................... 9

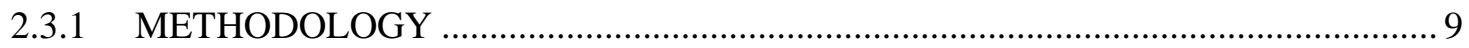

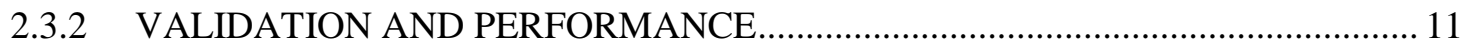

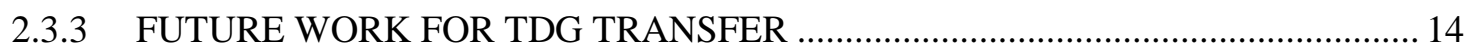

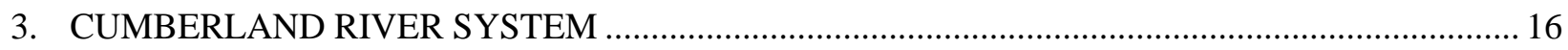

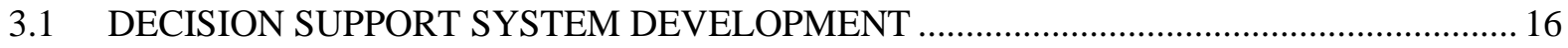

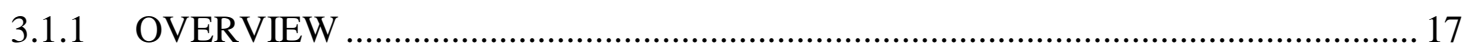

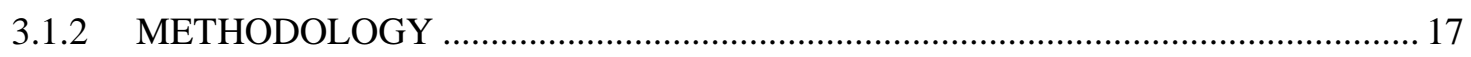

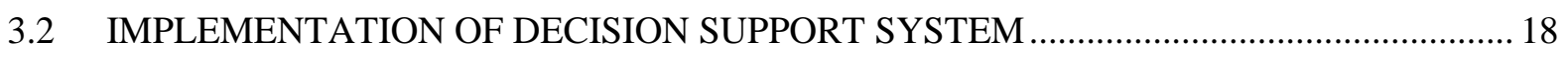

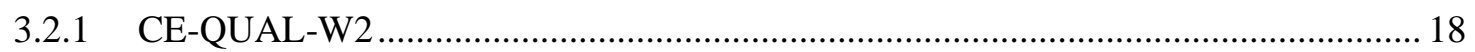

3.2.2 NONLINEAR AUTOREGRESSIVE NETWORK (NARX) MODEL ....................... 19

3.3 DECISION SUPPORT SYSTEM OPTIMIZATION ...................................................... 21

3.3.1 OLD HICKORY AND CORDELL HULL OPTIMIZATION RESULTS .................... 22

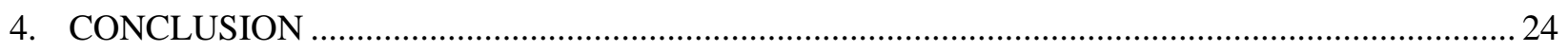

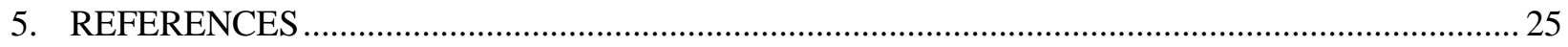




\section{LIST OF FIGURES}

Figure

Page

Figure 1- Map depicting major dams along the Columbia and Snake Rivers. The Study area (mid-

C) is highlighted in yellow Source: U.S. Army Corps of Engineers. Source:(2015

online)......

Figure 2 - Schematic of the TDG Uptake and TDG Transfer components of TDG prediction development along a river system. The red outline boxes refers to areas relevant in the prediction methodologies. The TDG Transport methodology is applied between the hydropower facilities. The TDG Uptake methodology is applied at the downstream side of a hydropower facility. The upstream impoundment corresponds to the location containing the important parameters for TDG transport determination. Likewise, the downstream impoundment corresponds to the location containing the predicted parameters for the TDG uptake determination.

Figure 3 - Comparison of simulated (solid black line) and measured (scatter points colored by spill flow) tailrace TDG during the summer of 2009 for (a) Grand Coulee, (b) Chief Joseph, (c) Wells, (d) Rocky Reach, (e) Rock Island, (f) Wanapum, and ( $g$ ) Priest Rapids. In general, the model performs well by conservatively capturing the peak TDG values.

Figure 4 - Time-series plot of RiverWare results for outflow TDG values with (Case 1) and without (Base Case) optimization to minimize TDG for Priest Rapids. The results of minimizing the TDG is indicative in the smoothing of the Base Case (orange) as depicted in the Case 1 (green).

Figure 5 - Time-series plot of RiverWare results for generation for Case 2 optimization to constrain TDG at $110 \%$ for Priest Rapids. Maintaining tailrace TDG values at $110 \%$ results in tradeoffs of reduced spill for increased generation. For periods of originally lower than $110 \%$ TDG, the model results indicate a sacrifice of generation for increased spill in the overall optimization process.

Figure 6 - Plots of upstream (Wanapum) and downstream (Priest Rapids) TDG (blue and red scatter points, respectively) with spill (green line) over the course of three days (top and bottom figures). The top figure represents data as measured. The middle figure provides an example of the cross-correlation results for upstream and downstream TDG. The $x$ axis displays the lag time while the y axis depicts the strength of the correlation for each lag time. The correlation is strongest at 13 hours, indicating peaks in upstream TDG due to spillway releases are measured in the downstream reservoir approximately 13 hours later. The bottom figure shifts the downstream TDG values up by 13 hours to highlight the correlation between TDG profiles due to a temporal lag. 
Figure 7 - Plot of relationship for tailrace TDG travel (lag) time between Wanapum and Priest Rapids as a function of mean upstream (Wanapum) powerhouse and spill flow. Scatter points are colored by the strength of the correlation at the given travel time $\left(C_{T D G}\right)$, and the power law best fit equation and $R^{2}$ are shown at the bottom left.

Figure 8 - Plot of relationship for tailrace TDG travel (lag) time between Rock Island and Wanapum as a function of mean upstream (Rock Island) powerhouse and spill flow. Scatter points are colored by the strength of the correlation at the given travel time $\left(C_{T D G}\right)$, and the power law best fit equation and $R^{2}$ are shown at the bottom left.

Figure 9 - Plot of relationship for tailrace TDG travel (lag) time between Rocky Reach and Rock Island as a function of mean upstream (Rocky Reach) powerhouse and spill flow. Scatter points are colored by the strength of the correlation at the given travel time $\left(C_{T D G}\right)$, and the best fit equation and $R^{2}$ are shown at the bottom left.

Figure 10 - Plot of relationship for tailrace TDG travel (lag) time between Wells and Rocky Reach as a function of mean upstream (Wells) powerhouse and spill flow. Scatter points are colored by the strength of the correlation at the given travel time $\left(C_{T D G}\right)$, and the best fit equation and $R^{2}$ are shown at the bottom left.

Figure 11 - Plot of relationship for tailrace TDG travel (lag) time between Chief Joseph and Wells as a function of mean upstream (Chief Joseph) powerhouse and spill flow. Scatter points are colored by the strength of the correlation at the given travel time $\left(C_{T D G}\right)$, and the best fit equation and $R^{2}$ are shown at the bottom left.

Figure 12 - Plot of relationship for tailrace TDG travel (lag) time between Grand Coulee and Chief Joseph as a function of mean upstream (Grand Coulee) powerhouse and spill flow. Scatter points are colored by the strength of the correlation at the given travel time $\left(C_{T D G}\right)$, and the best fit equation and $R^{2}$ are shown at the bottom left.

Figure 13 - Preliminary results plot of TDG transfer magnitude prediction between Wanapum and Priest Rapids. The results are presented for two different cases - one based on no flow class separation and one using flow class separation. For the no flow class separation, only one predictive equation, independent of flow is used. For the flow class separation, 5 separate equations each pertaining to different ranges of flow are used to estimate reservoir TDG levels. Predictive performance for the two approaches are almost identical exhibiting a slight tendency for over predicting TDG levels.

Figure 14 - Projects along the Cumberland River (courtesy of USACE Nashville District). Of interest to the current project are the Cordell Hull and Old Hickory reservoirs circled in the figure.

Figure 15 - Overall approach methodology for the decision-support system development illustrating the reduction of high-fidelity W2 model results into a useful input for use in optimization.

Figure 16 - CE-QUAL W2 example simulation results for Old Hickory flow used as training data sets for the neural network. 
Figure 17 - Distribution of temperature and dissolved oxygen prediction errors for the training and validation data sets for Old Hickory. The training and validation have similar distributions indicating the neural network's predictive power.

Figure 18 - Comparison of discharge temperature prediction from the NARX and W2 model results for Old Hickory. The comparison of the two plots indicate that the neural network's performance for prediction of temperature is very good.

Figure 19 - Comparison of discharge dissolved oxygen prediction from the NARX and W2 model results for Old Hickory. . The comparison of the two plots indicate that the neural network's performance for prediction of dissolved oxygen is very good.

Figure 20 - Turbine discharge flow results for optimization of generation at Old Hickory. The optimal solution for the maximization of generation is characterized by spikes in turbine discharge in contrast to the 2005 operations that are indicative of longer periods of lower turbine discharge.

Figure 21 - Turbine discharge temperature results for optimization of generation at Old Hickory yields an overall lower discharge temperature.

Figure 22 - Headwater elevation results for optimization of generation at Old Hickory did not change significantly from those associated with the 2005 operations.

\section{LIST OF TABLES}

Table

Page

Table 1 - Coefficients results and performance statistics for TDG uptake predictions. 4 


\section{ACKNOWLEDGMENTS}

The authors would like to acknowledge and express their appreciation to all the following individuals and programs for their review, comments, and support of this report:

IIHR - Engineering and Hydroscience at University of Iowa

- Marcela Politano

- Alejandro Castro

- Larry Weber

\section{CADSWES}

- Edith Zagona

- Timothy McGee

- David Neumann

- Mitch Clement

\section{USBR}

- Merlynn Bender

- Kerry McCalman

- Michael Pulskamp

\section{U.S. ARMY CORPS OF ENGINEERS (PORTLAND DISTRICT)}

- William Proctor

- Scott English

\section{U.S. ARMY CORPS OF ENGINEERS (NASHVILLE DISTRICT)}

- Bob Sneed

- Mike Wilson

\section{CHELAN COUNTY PUD}

- Martha Whiteman

- Waikele Frantz

- Scott Buehn

\section{MID-C COORDINATION}

- Joe Taylor

\section{VANDERBILT UNIVERSITY}

- Dr. Eugene J. LeBoeuf

- Amy Shaw

- Heather Smith Sawyer 


\section{LIPSCOMB UNIVERSITY}

- Dr. Mark McDonald

\section{OAK RIDGE NATIONAL LABORATORY}

- Scott DeNeale

- Ethan Hopping

- Abigail Maloof

- Nicole Samu 


\begin{tabular}{|c|c|}
\hline & ABBREVIATIONS \\
\hline CADSWES & $\begin{array}{l}\text { University of Colorado's Center for Advanced Decision Support for Water and } \\
\text { Environmental Systems }\end{array}$ \\
\hline CRiSP & Columbia River Salmon Passage \\
\hline DOE & Department of Energy \\
\hline IIHR & Iowa Institute of Hydraulic Research \\
\hline kcfs & thousand cubic feet per second \\
\hline NARX & Nonlinear AutoRegressive network with eXogenous inputs \\
\hline ORNL & Oak Ridge National Laboratory \\
\hline RMSE & Root Mean Square Error \\
\hline SYSTDG & System Total Dissolved Gas \\
\hline TDG & Total Dissolved Gas \\
\hline USACE & United States Army Corps of Engineers \\
\hline W2 & short nomenclature for CE-QUAL-W2 software name \\
\hline
\end{tabular}




\begin{abstract}
Scheduling and operational control of hydropower systems is accompanied with a keen awareness of the management of water use, environmental effects, and policy, especially within the context of strict water rights policy and generation maximization. This is a multi-objective problem for many hydropower systems, including the Cumberland and Mid-Columbia river systems. Though each of these two systems have distinct operational philosophies, hydrologic characteristics, and system dynamics, they both share a responsibility to effectively manage hydropower and the environment, which requires state-of-the art improvements in the approaches and applications for water quality modeling.

The Department of Energy and Oak Ridge National Laboratory have developed tools for total dissolved gas (TDG) prediction on the Mid-Columbia River and a decision-support system used for hydropower generation and environmental optimization on the Cumberland River. In conjunction with IIHR Hydroscience \& Engineering, The University of Iowa and University of Colorado's Center for Advanced Decision Support for Water and Environmental Systems (CADSWES), ORNL has managed the development of a TDG predictive methodology at seven dams along the Mid-Columbia River and a methodology for optimization of operations at these projects is now available through the commercial software package RiverWare. ORNL has also managed a collaboration with Vanderbilt University and Lipscomb University to develop a state-of-the art method for reducing high-fidelity water quality modeling results into surrogate models, which can be used in river system optimization efforts to maximize generation based on environmental and policy constraints.

The novel contribution of these efforts is the ability to predict water quality conditions with simplified methodologies at the same level of accuracy as more complex and resource intensive computing methods. These efforts were designed to incorporate well into existing hydropower and reservoir system scheduling models, with runtimes that are comparable to existing software tools. In addition, the transferability of these tools to assess other systems is enhanced due the use of simplistic and easily attainable values for inputs, straight-forward calibration of predictive equation coefficients, and standardized comparison of traditionally familiar outputs.
\end{abstract}




\section{BACKGROUND AND INTRODUCTION}

Oak Ridge National Laboratory (ORNL) for the U.S. Department of Energy (DOE) has managed the completion of project for the prediction of total dissolved gas (TDG) uptake for seven Mid-Columbia River dams in conjunction with Iowa Hydroscience \& Engineering Department at the University of Iowa and CADSWES with the University of Colorado, and the completion of the Decision-Support System for the Cumberland River in conjunction with Vanderbilt and Lipscomb Universities.

The objective of the Mid-Columbia River TDG uptake prediction project is to establish generalized simplified equations for predicting TDG uptake that are calibrated specifically for each of the seven projects along the Mid-Columbia River. The resulting equations and calibration information are integrated into the RiverWare software and used to demonstrate the effect of optimizing operations based on TDG constraints. The deliverable of "Total Dissolved Gas Prediction and Optimization in RIVERWARE" delivered to DOE in September of 2015 (Stewart et al. 2015) contains results of the calibration and validation of these efforts. Funds remaining following the completion of this project were used to explore the feasibility of developing a methodology for the prediction of the timing and magnitude of TDG transfer along the reservoir system. This report provides a summary of the development, implementation, and optimization results of the TDG uptake work as well as the preliminary results and future considerations for the TDG transfer work.

The objective of the Cumberland River Decision Support System project is to develop a product capable of performing a rule-based simulation and optimization of hydropower and reservoir system performance subject to constraints placed on hydropower generation, water quality, and multi-purpose policies of the reservoir system. This report provides a summary of the development, implementation, and optimization results of the Decision Support System work for the Cumberland River.

\section{MID-COLUMBIA RIVER SYSTEM}

The TDG uptake and transfer work is performed for 7 projects on the mid-Columbia river system (Figure 1) and includes Grand Coulee, Chief Joseph, Wells, Rocky Reach, Rock Island, Wanapum, and Priest Rapids which contain elevated levels of total dissolved gas (TDG) concentrations in the downstream tailraces resulting from spill operations. Based on the detrimental effect of TDG on fish, provisions for remedying or reducing percentage levels at many projects is a significant priority in the operation of the hydropower facilities. 


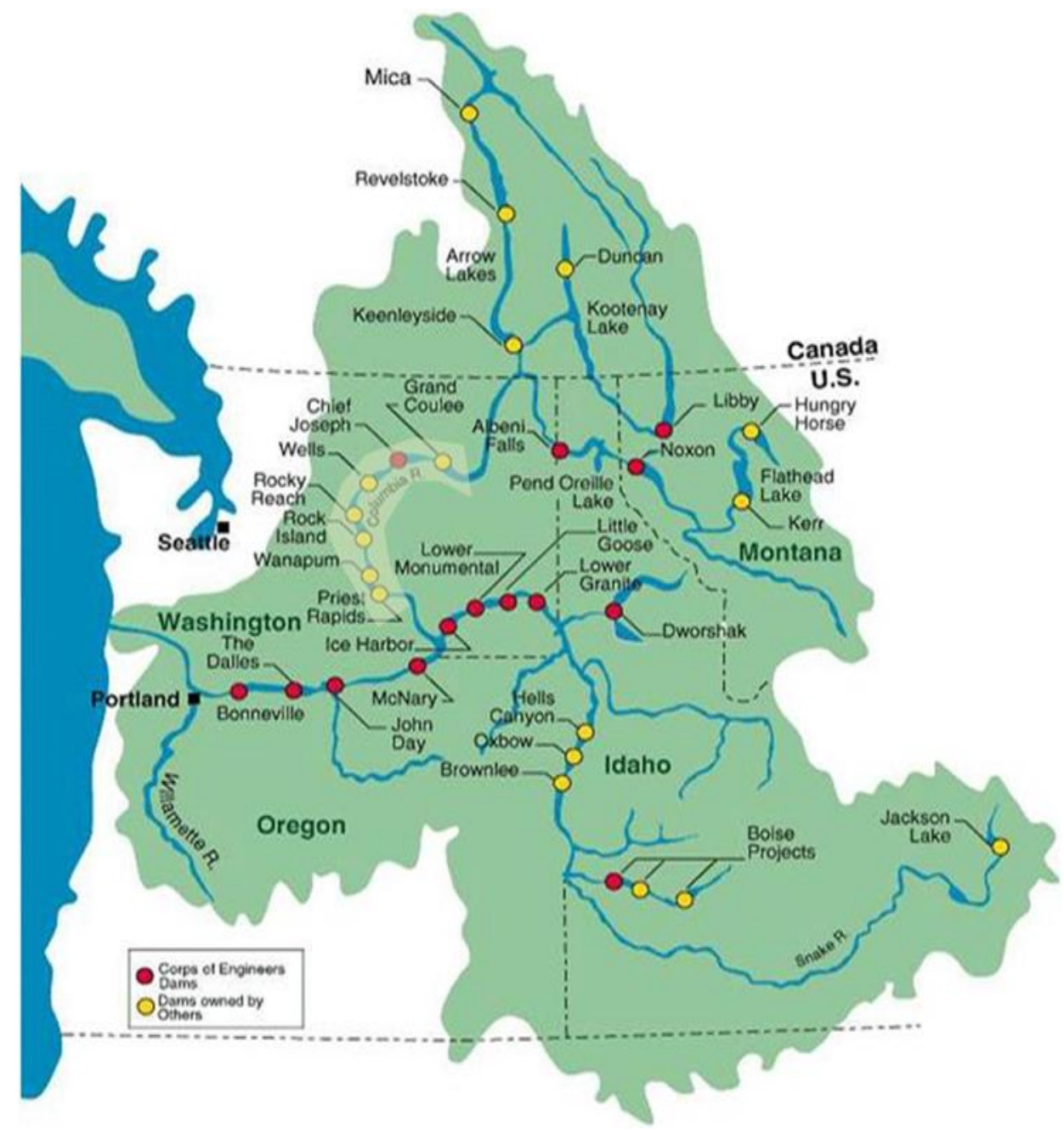

Figure 1- Map depicting major dams along the Columbia and Snake Rivers. The Study area (midC) is highlighted in yellow Source: U.S. Army Corps of Engineers. Source:(2015 online).

The TDG prediction efforts include two distinct areas of focus - TDG uptake and TDG transfer. As illustrated in Figure 2, the TDG uptake method predicts tailrace TDG based on forebay TDG, spill flow, and the mixing characteristics of the dam. The TDG transfer method predicts TDG in the forebay of a downstream reservoir as a function of the tailrace TDG at an upstream reservoir. 


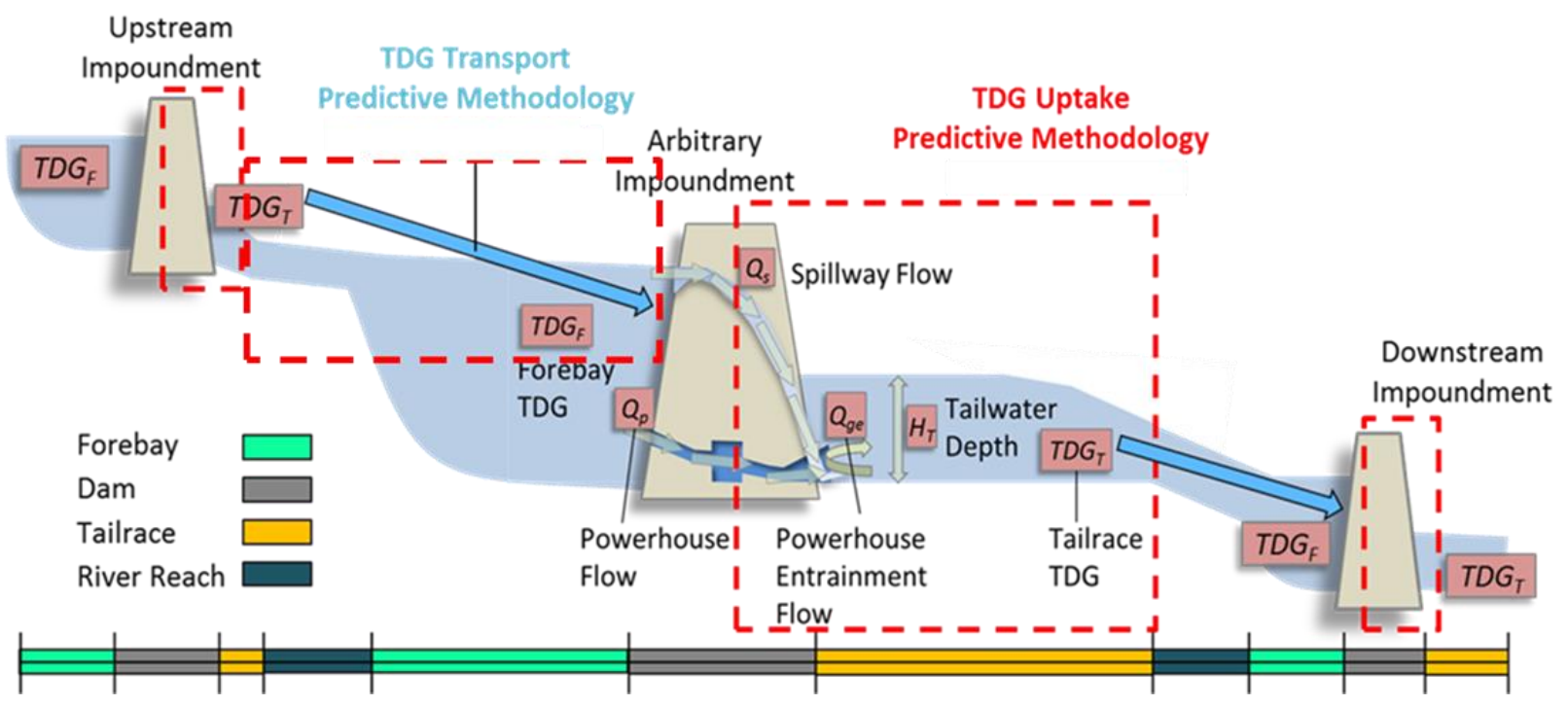

Figure 2 - Schematic of the TDG Uptake and TDG Transfer components of TDG prediction development along a river system. The red outline boxes refers to areas relevant in the prediction methodologies. The TDG Transport methodology is applied between the hydropower facilities. The TDG Uptake methodology is applied at the downstream side of a hydropower facility. The upstream impoundment corresponds to the location containing the important parameters for TDG transport determination. Likewise, the downstream impoundment corresponds to the location containing the predicted parameters for the TDG uptake determination.

\subsection{TDG UPTAKE PREDICTION DEVELOPMENT}

The University of Iowa (IIHR - Hydroscience \& Engineering) developed the methods and equations used to predict TDG uptake based on physical measurements and correlative analyses. ORNL calibrated and validated the equations with approximately 8 years of water quality data containing unit and spill flows, headwater and tailwater elevations along with concentrations of TDG obtained online from the USACE Northwestern Division's Dataquery system. ORNL worked with University of Colorado's CADSWES to implement the TDG uptake equations within the RiverWare software. A full description of the methodology and results can be found in Witt et al. (2016) ${ }^{1}$.

\subsubsection{METHODOLOGY}

The TDG prediction methodologies are based on the need to incorporate a predictive methodology into a real-time hydropower forecasting system. This precludes the option of utilizing methods and models that directly model the physical processes as this requires significant overhead in resources and time, not to mention the difficulty in incorporating this into a hydropower systems modeling software. Empirical approaches are more appropriate and utilized herein to predict TDG uptake and TDG transfer.

1 Article is available upon request to the authors. 
The TDG uptake methodology is based on the regression of water quality data yielding a set of simplified expressions for predicting uptake at a hydropower tailrace (Stewart et al. 2015). This simplified approach utilizes variables such as powerhouse and spill flow, head and tailwater elevations, and headwater ambient TDG concentrations that are measured at each facility. The components of the predictive equations represent effects due to tailwater depth on the production of TDG as well as the effect of powerhouse and spillway entrainment flow on the background TDG concentration levels in the forebay. The equations are calibrated for each of the seven Mid-Columbia hydropower sites using three different coefficients.

\subsubsection{VALIDATION AND PERFORMANCE}

Statistical results of the TDG uptake prediction methodology calibration and validation are provided in Table 1. In general, the coefficient of determination is very good for the calibrated and validated cases with very low root-mean square errors (RMSE) percentages. The performance of the model over two months in July 2009 is shown in Figure 3 for all seven hydropower facilities. The model captures a number of distinct system characteristics well, including the range of maximum to minimum tailrace TDG throughout the system, the daily and weekly fluctuations in tailrace TDG, the overall system variability in TDG magnitude, and most importantly, the project specific dependence of TDG uptake on spillway flow.

Table 1 - Coefficients results and performance statistics for TDG uptake predictions.

\begin{tabular}{||l|cc|lc||}
\hline \hline \multirow{2}{*}{ Project Site: } & \multicolumn{2}{|c|}{ Calibrated with 2008-2010 data } & \multicolumn{2}{|c|}{ Validated with 2004-2012 data } \\
\cline { 2 - 5 } & $R^{2}$ & $R M S E(\%)$ & $R^{2}$ & $R M S E(\%)$ \\
\hline \hline Grand Coulee & 0.793 & 2.33 & 0.997 & 4.15 \\
\hline Chief Joseph & 0.093 & 2.54 & 0.930 & 1.54 \\
\hline Wells & 0.958 & 0.94 & 0.958 & 1.28 \\
\hline Rocky Reach & 0.857 & 1.51 & 0.921 & 1.51 \\
\hline Rock Island & 0.952 & 1.27 & 0.942 & 1.38 \\
\hline Wanapum & 0.932 & 1.69 & 0.930 & 2.05 \\
\hline Priest Rapids & 0.966 & 1.10 & 0.972 & 1.42 \\
\hline
\end{tabular}




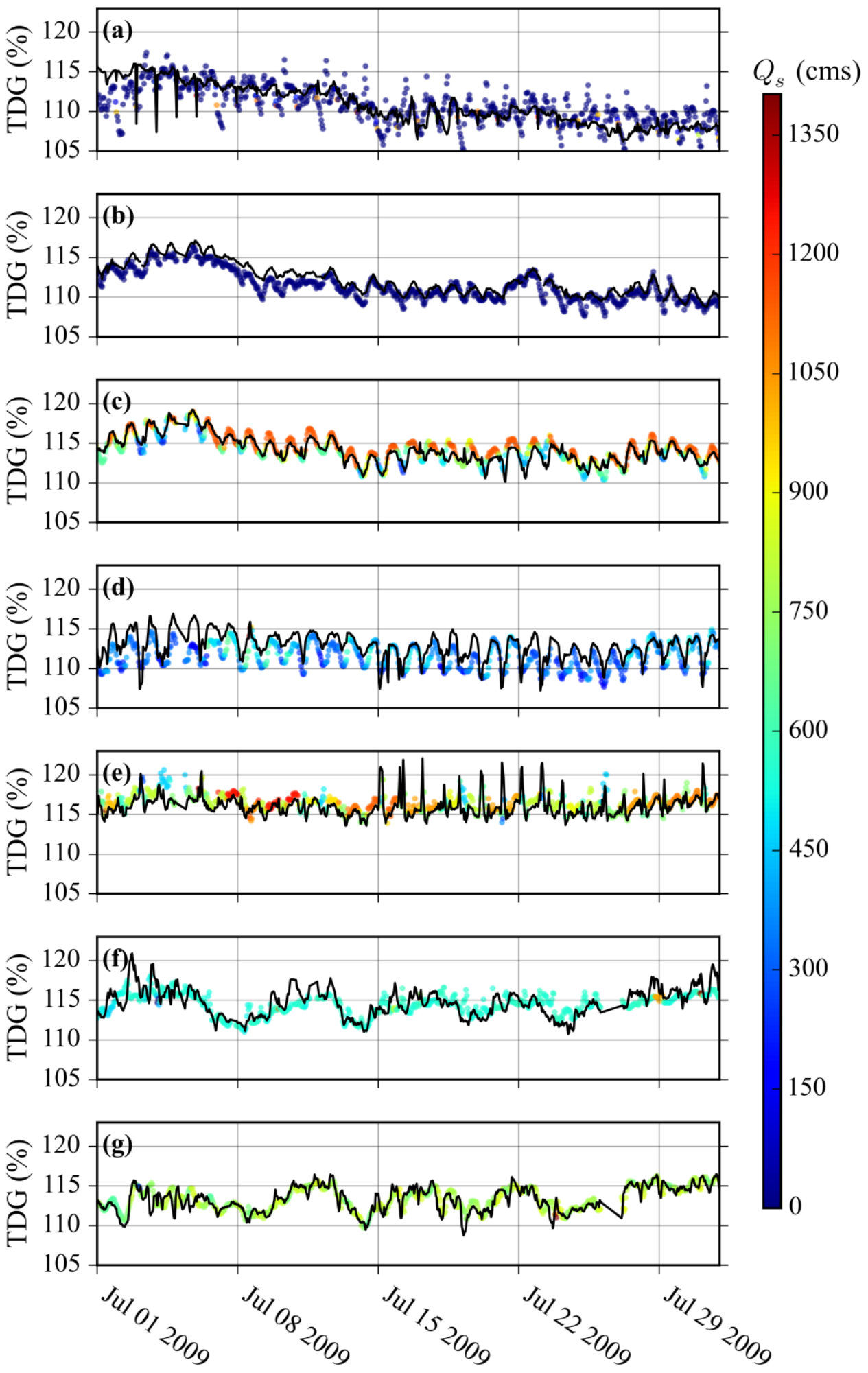

Figure 3 - Comparison of simulated (solid black line) and measured (scatter points colored by spill flow) tailrace TDG during the summer of 2009 for (a) Grand Coulee, (b) Chief Joseph, (c) Wells, (d) Rocky Reach, (e) Rock Island, $(f)$ Wanapum, and ( $g$ ) Priest Rapids. In general, the model performs well by conservatively capturing the peak TDG values. 


\subsection{IMPLEMENTATION OF TAILRACE TDG DEVELOPMENT INTO RIVERWARE}

The TDG uptake predictive equations with the calibration information for each of the seven hydropower sites are incorporated into the RiverWare software.

\subsubsection{OVERVIEW OF MID-COLUMBIA OPTIMIZATION MODEL}

Prior to the development and incorporation of the TDG predictive methodology in the RiverWare model, CADSWES had already developed a Mid-Columbia RiverWare model used by PUDs in the northwest U.S. This model incorporates an optimization operations model for performing optimization of 3 or more days at hourly time steps. It also incorporates autoregressive flows downstream of Priest Rapids. The policy component of the model is divided into two groups - the federal and nonfederal projects. For the federal projects, the policy model utilizes high priority goals with conservative assumptions that are not intended to realistically model federal policy but are rather used to globally obtain correct inflows for projects. The non-federal projects policy model is intended to be realistic with many environmental constraints that act to roughly minimize water used by the projects.

\subsubsection{RIVERWARE'S TDG METHODS}

RiverWare currently incorporates some level of TDG methods in its water quality applications that can be enabled or disabled and can be calculated as an "inline" process or as a "post" process (at end of the model run). RiverWare has historically used equations from the Columbia River Salmon Passage (CRiSP) model and the SYSTDG-USACE to determine outflow TDG (Zagona et al. 2012). The current contribution of TDG uptake prediction utilizes calibrated and validated equations specific to each site. Currently, there is only an option to specify a single time lag for TDG as it is transferred from upstream to downstream.

\subsubsection{PRIEST RAPIDS TAILRACE TDG OPTIMIZATION}

CADSWES performed an optimization for TDG minimization at Priest Rapids reservoir for three different scenarios within RiverWare. A base case for no optimization of TDG is performed and plotted in Figure 4 for Priest Rapids outflow. In addition, two optimization runs to constrain TDG are made, but with different constraint priority assignments. Case 1 run is made such that the constraint of TDG is assigned a lower priority than power system constraints, and the Case 2 run assigns a higher priority to TDG constraints than power system constraints.

The results of Case 1 are plotted in Figure 4 as the resulting TDG level in the tailrace of Priest Rapids. It can be observed that the optimization scheme aims to follow the soft constraint of trying to maintain TDG levels at an environmentally imposed maximum level of $110 \%$ especially for time periods after July 4 . It is observed that the spike of TDG for the base case is greatly reduced with the optimization scheme but with perhaps a tradeoff of increases of lower values of TDG values a day later.

For Case 2, Figure 5 indicates the surpluses and shortfalls in generation resulting from assigning a higher priority to the execution of the TDG constraints. To maintain the tailrace TDG values at $110 \%$, water 
balance efforts over the 3-day period of study tend to result in a tradeoff of reduced spill for increased generation as is indicative for the July $3^{\text {rd }}$ to July $4^{\text {th }}$ time period. Also, for periods of originally lower than $110 \%$ TDG (July $4^{\text {th }}$ to July $5^{\text {th }}$ ), the model results sacrifice generation for increased spill.

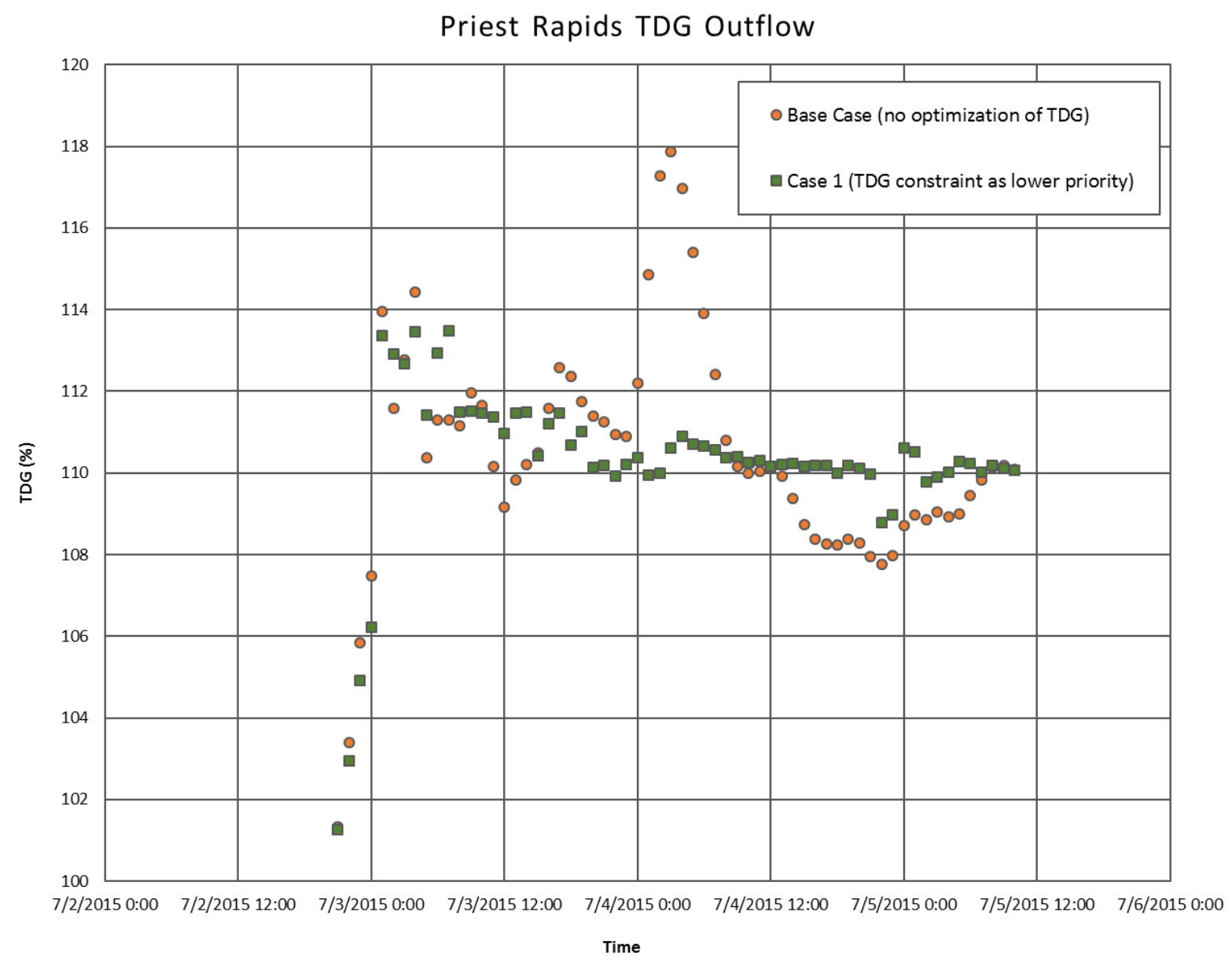

Figure 4 - Time-series plot of RiverWare results for outflow TDG values with (Case 1) and without (Base Case) optimization to minimize TDG for Priest Rapids. The results of minimizing the TDG is indicative in the smoothing of the Base Case (orange) as depicted in the Case 1 (green). 
Generation Surplus and Shortfall

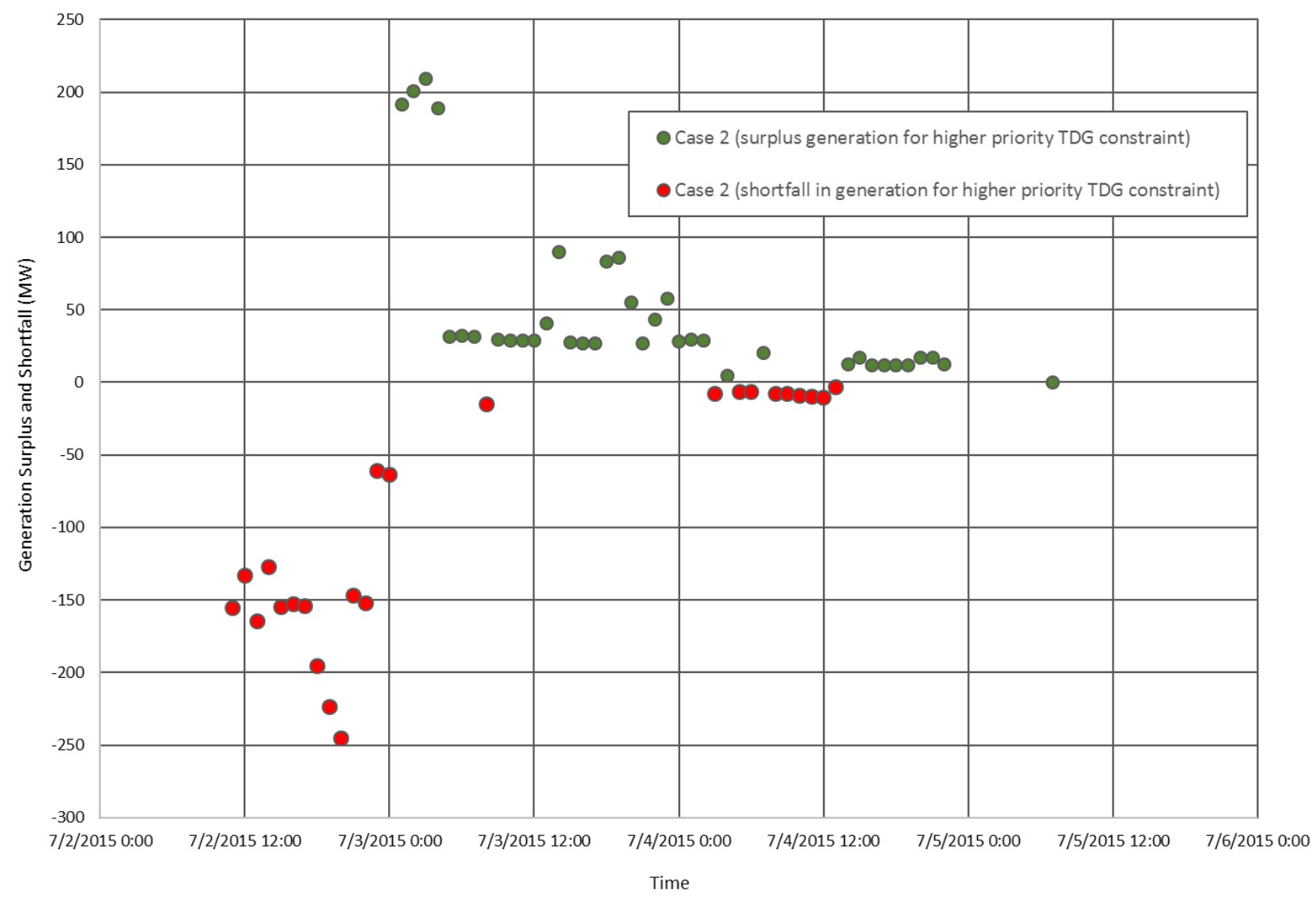

Figure 5 - Time-series plot of RiverWare results for generation for Case 2 optimization to constrain TDG at $110 \%$ for Priest Rapids. Maintaining tailrace TDG values at $110 \%$ results in tradeoffs of reduced spill for increased generation. For periods of originally lower than $110 \%$ TDG, the model results indicate a sacrifice of generation for increased spill in the overall optimization process.

\subsubsection{SIGNIFICANCE OF RESULTS}

The innovations outlined in this work represent two significant advances in TDG and hydropower management: (1) the simplified predictive techniques for TDG uptake are accurate with uncertainties consistent with more complex methodologies, and (2) the simplified equation is amenable to a mathematically advantageous treatment in a more complex optimization software, which leads to unprecedented examination of TDG and hydropower tradeoffs under different operating policy scenarios. This tool opens the door to a new range of possibilities with respect to hourly coordination among projects. The overall approach can be extended to other reservoir systems to advance hydropower operators knowledge and management of complex environmental and energy objectives and constraints. 


\subsection{TDG TRANSFER PREDICTION}

The TDG transfer prediction is a separate effort to the TDG uptake work conducted by ORNL and is a necessary component for being able to effectively predict TDG concentrations along the Mid-C river system as it "fills" in the gap regarding how the predicted uptake of TDG is transferred along a reservoir. The current equations used in RiverWare do not accurately reflect the time-dependent nature of TDG transfer. The development utilizes the same set of data used for the TDG uptake predictions. ORNL collaborated with University of Colorado's CADSWES to help establish the most effective approach for incorporating the TDG transfer prediction methods into RiverWare.

\subsubsection{METHODOLOGY}

The TDG transfer methodology is based on the prediction of the timing and magnitude of the TDG levels as they travel from the tailrace of a hydropower facility to the forebay of the downstream facility. The temporal aspect of the TDG transport refers to predicting when the increased TDG is likely to be measured at downstream facilities. The magnitude refers to how much the magnitude of TDG is reduced when measured at downstream facilities.

The prediction of the timing of the TDG is based on cross correlation of the upstream and downstream TDG concentrations for events with strong daily variations in spill and TDG (Figure 6 top). The lag time as a function of the correlation coefficient (Figure 6 middle) indicates the degree of dependence of the downstream TDG with that of the upstream TDG for specific lag times. A good alignment of time-shifted TDG peaks indicates strong correlation (Figure 6 bottom).

Functions of TDG lag times as a function of powerhouse and spill flow can be derived using the results of the cross correlation method for filtered data sets. Filtering of the data used in the analysis is necessary to ensure only strong TDG pulse events are analyzed, and to eliminate noise in the final results. The filters include:

- Including data only from months between April through August

- Limiting the number of days included in the lag time calculation

- Limiting the standard deviation of upstream TDG

- Limiting the mean spillway flow

- Specifying specific range of lag times

- Limiting time lags corresponding to correlation coefficients greater than 0.35 . 

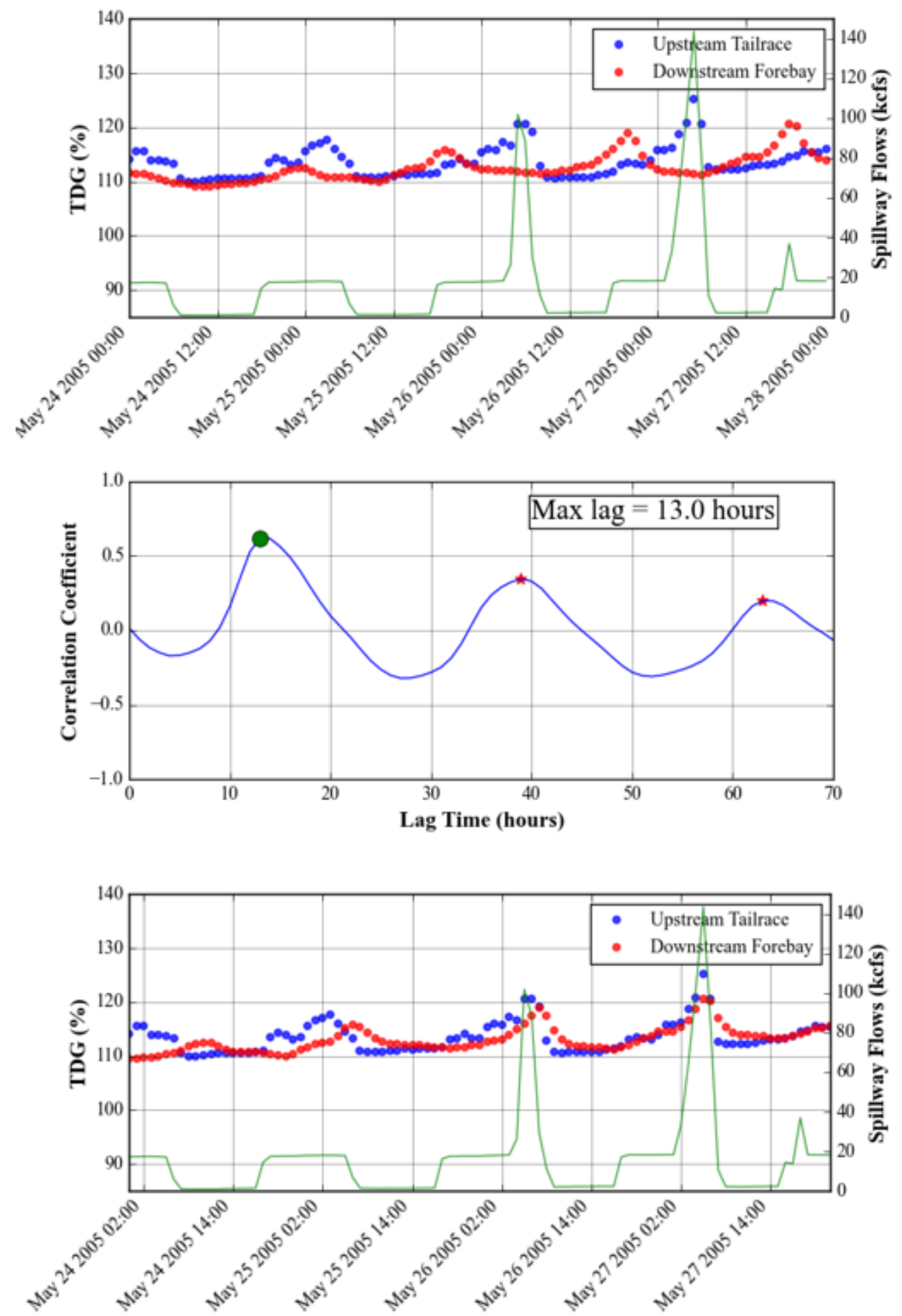

Figure 6 - Plots of upstream (Wanapum) and downstream (Priest Rapids) TDG (blue and red scatter points, respectively) with spill (green line) over the course of three days (top and bottom figures). The top figure represents data as measured. The middle figure provides an example of the cross-correlation results for upstream and downstream TDG. The x axis displays the lag time while the y axis depicts the strength of the correlation for each lag time. The correlation is strongest at 13 hours, indicating peaks in upstream TDG due to spillway releases are measured in the downstream reservoir approximately 13 hours later. The bottom figure shifts the downstream TDG values up by 13 hours to highlight the correlation between TDG profiles due to a temporal lag. 


\subsubsection{VALIDATION AND PERFORMANCE}

Results of the lag time as a function of hydropower facility flows for the TDG transfer are plotted in Figure 7 through Figure 12. In general, for power law "best fit" lines through the data, coefficients of determination range from roughly 0.6 to 0.8 , indicating a correlation between flow and lag time determined with cross correlation. The results for Wanapum to Priest Rapids (Figure 7) display the strongest relationship. These two reservoirs are separated by the shortest amount, indicating the lag time method reported herein may be sensitive to the distance in river miles between two reservoirs. The results for Rock Island to Wanapum (Figure 8) and Grand Coulee to Chief Joseph (Figure 12) give the poorest correlation of the six reservoirs. In each case, the two paired reservoirs are separated by over 40 river miles, and the natural diffusion, dissipation, and gas exchange that occurs over this distance may reduce the efficacy of a cross-correlation analysis that relies on a TDG front maintaining a similar shape over time. At Grand Coulee, much fewer spill events occur over the course of the year compared to other reservoirs, further limiting the data set available for analysis.

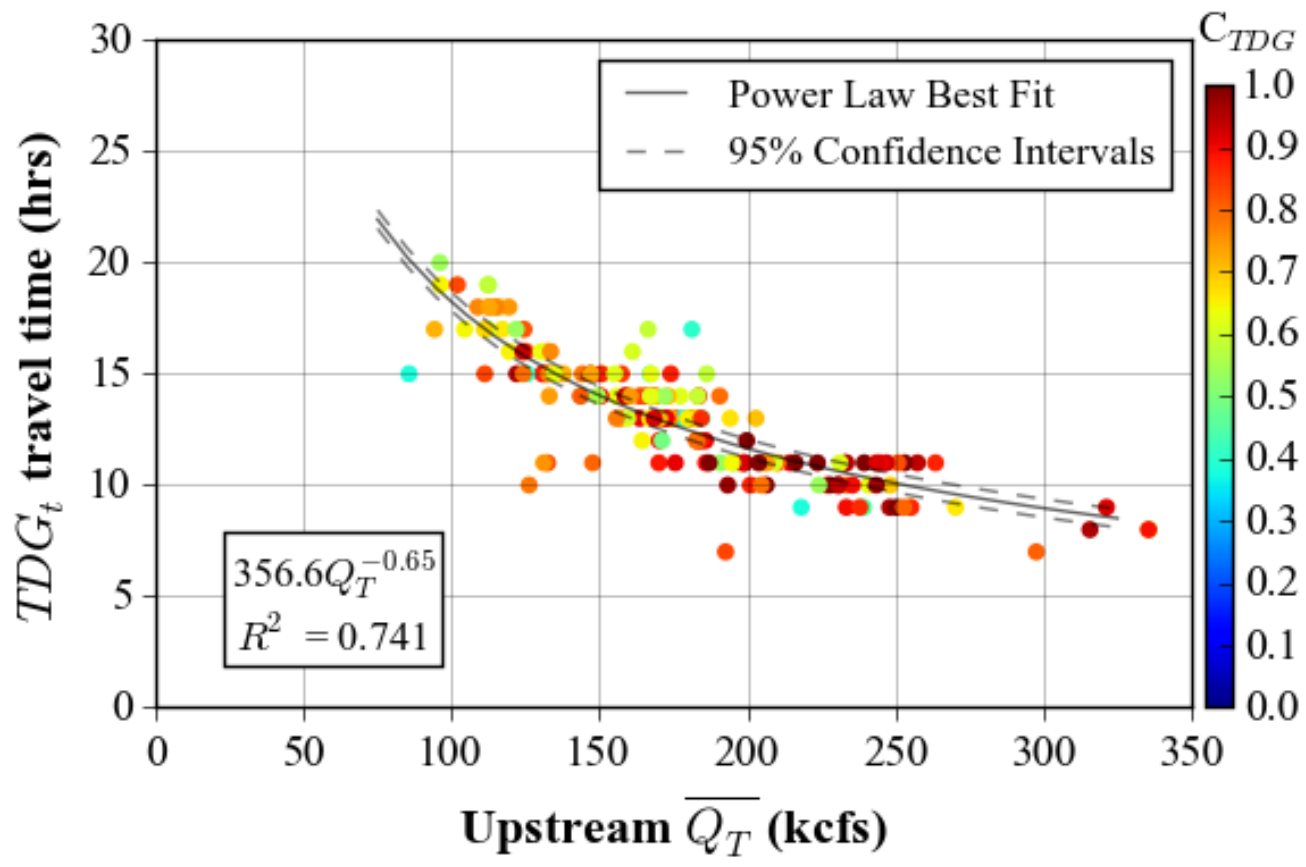

Figure 7 - Plot of relationship for tailrace TDG travel (lag) time between Wanapum and Priest Rapids as a function of mean upstream (Wanapum) powerhouse and spill flow. Scatter points are colored by the strength of the correlation at the given travel time $\left(C_{T D G}\right)$, and the power law best fit equation and $R^{2}$ are shown at the bottom left. 


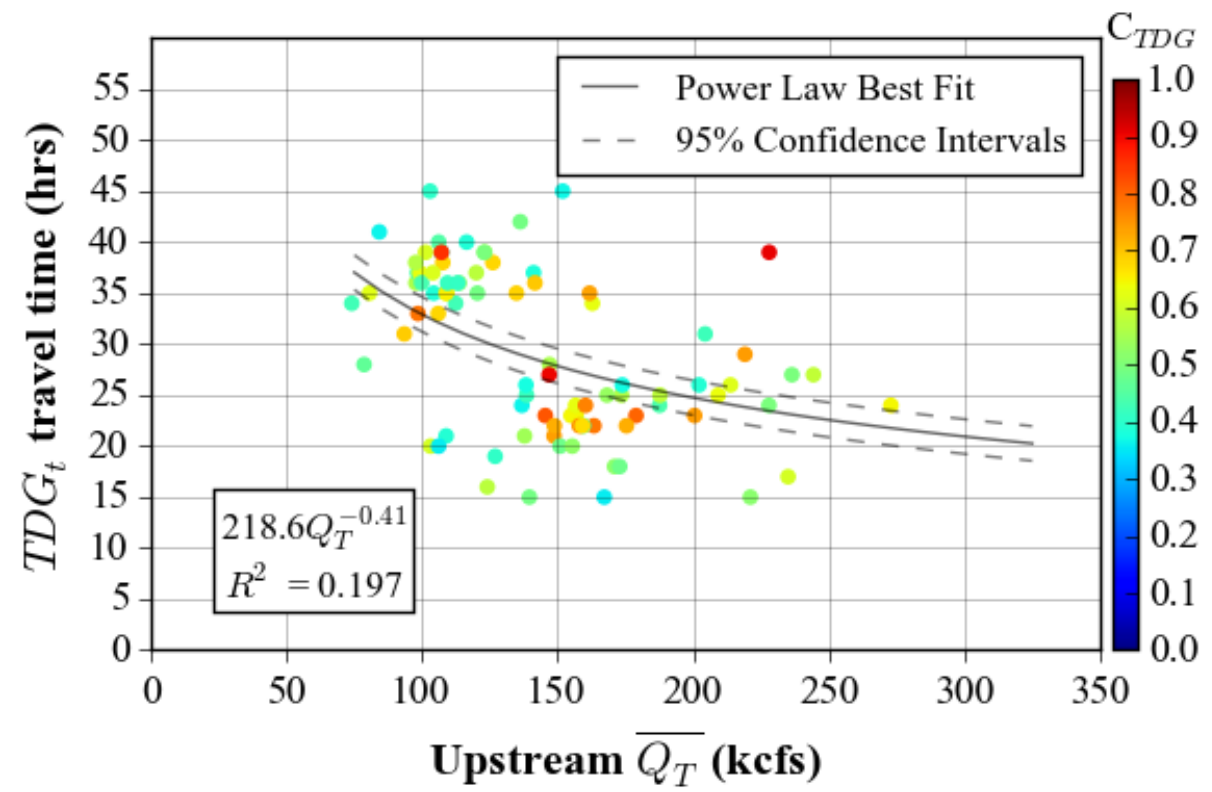

Figure 8 - Plot of relationship for tailrace TDG travel (lag) time between Rock Island and Wanapum as a function of mean upstream (Rock Island) powerhouse and spill flow. Scatter points are colored by the strength of the correlation at the given travel time $\left(C_{T D G}\right)$, and the power law best fit equation and $R^{2}$ are shown at the bottom left.

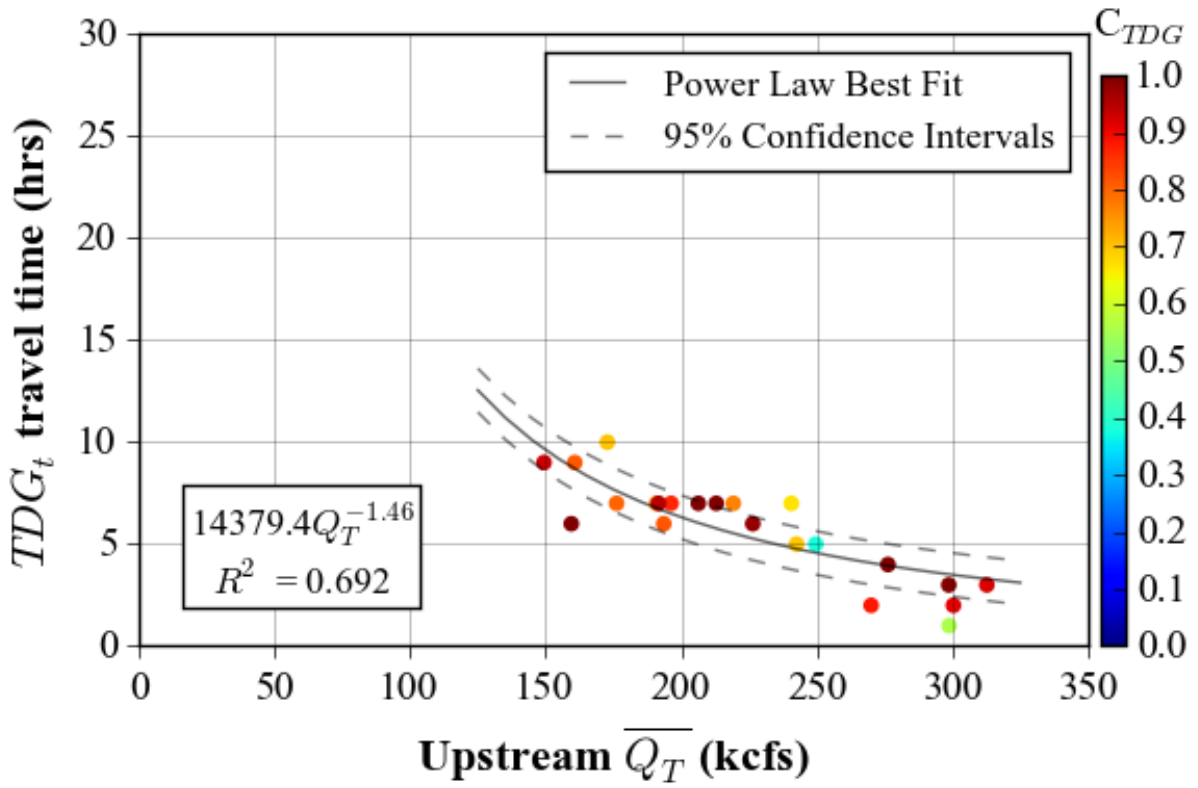

Figure 9 - Plot of relationship for tailrace TDG travel (lag) time between Rocky Reach and Rock Island as a function of mean upstream (Rocky Reach) powerhouse and spill flow. Scatter points are colored by the strength of the correlation at the given travel time $\left(C_{T D G}\right)$, and the best fit equation and $R^{2}$ are shown at the bottom left. 


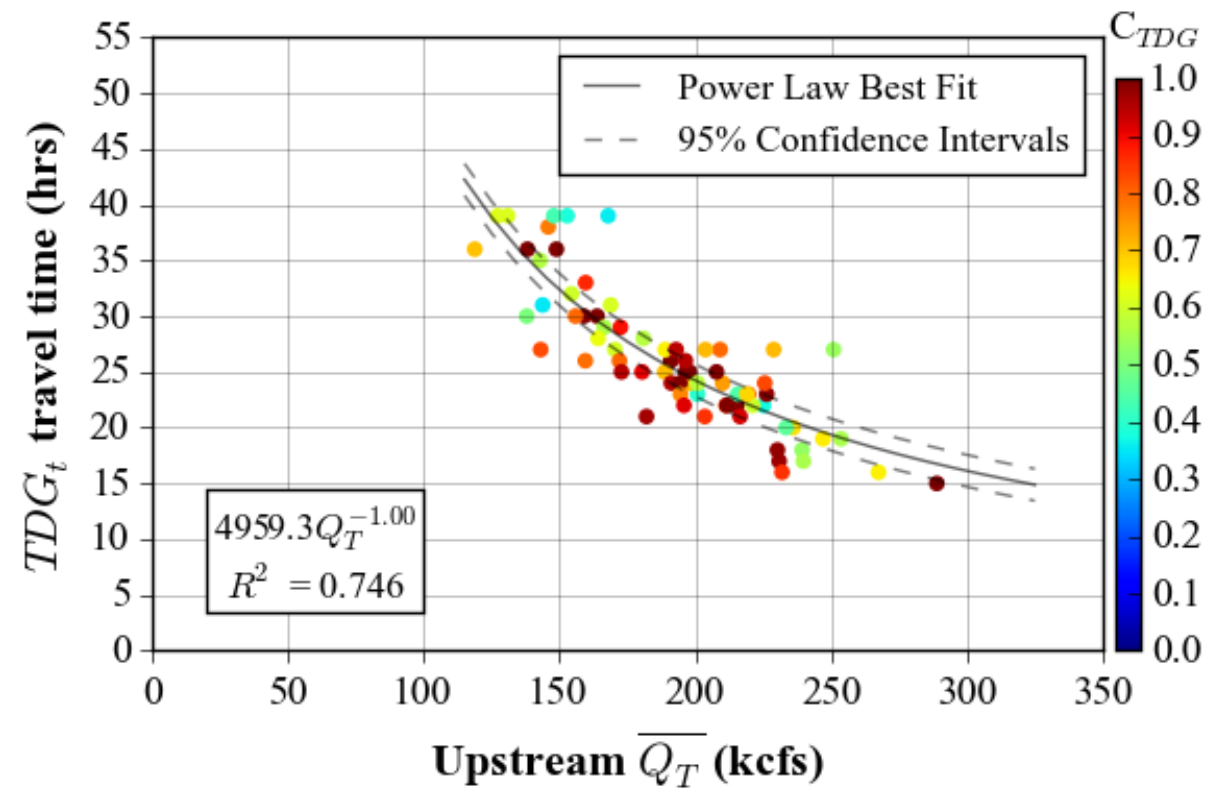

Figure 10 - Plot of relationship for tailrace TDG travel (lag) time between Wells and Rocky Reach as a function of mean upstream (Wells) powerhouse and spill flow. Scatter points are colored by the strength of the correlation at the given travel time $\left(C_{T D G}\right)$, and the best fit equation and $R^{2}$ are shown at the bottom left.

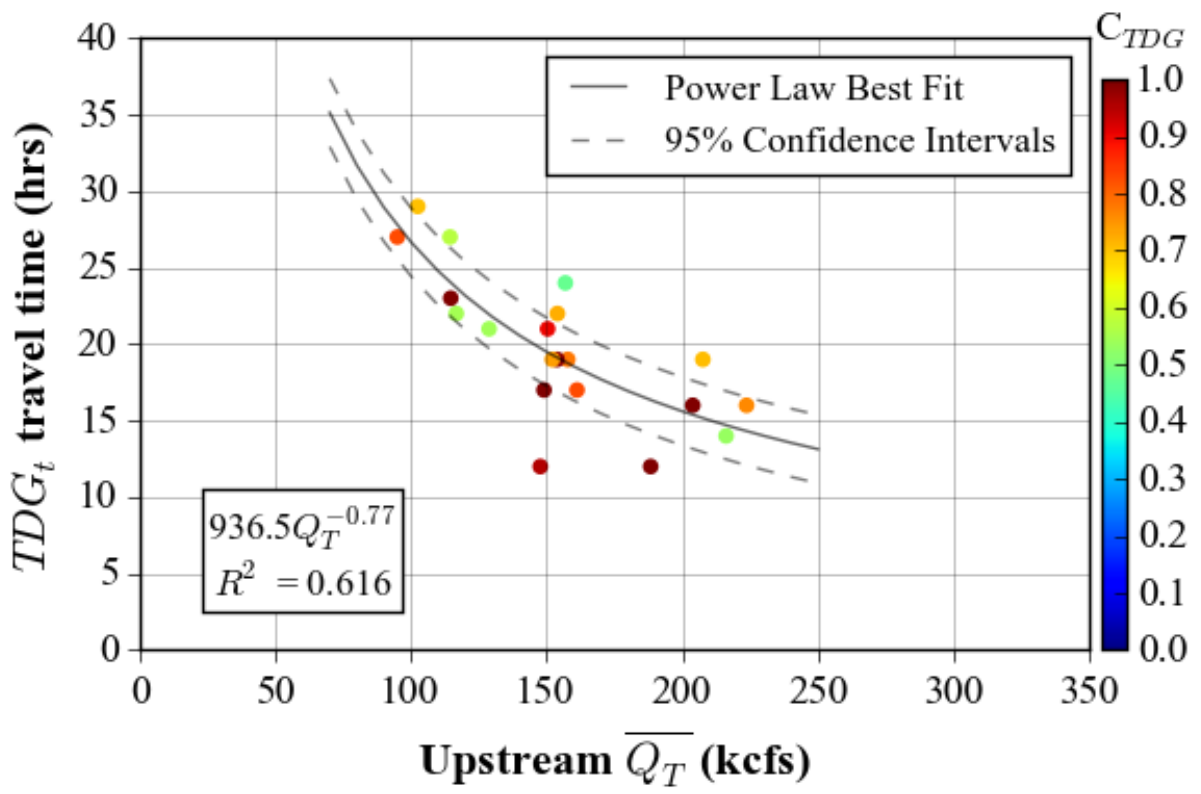

Figure 11 - Plot of relationship for tailrace TDG travel (lag) time between Chief Joseph and Wells as a function of mean upstream (Chief Joseph) powerhouse and spill flow. Scatter points are colored by the strength of the correlation at the given travel time $\left(C_{T D G}\right)$, and the best fit equation and $R^{2}$ are shown at the bottom left. 


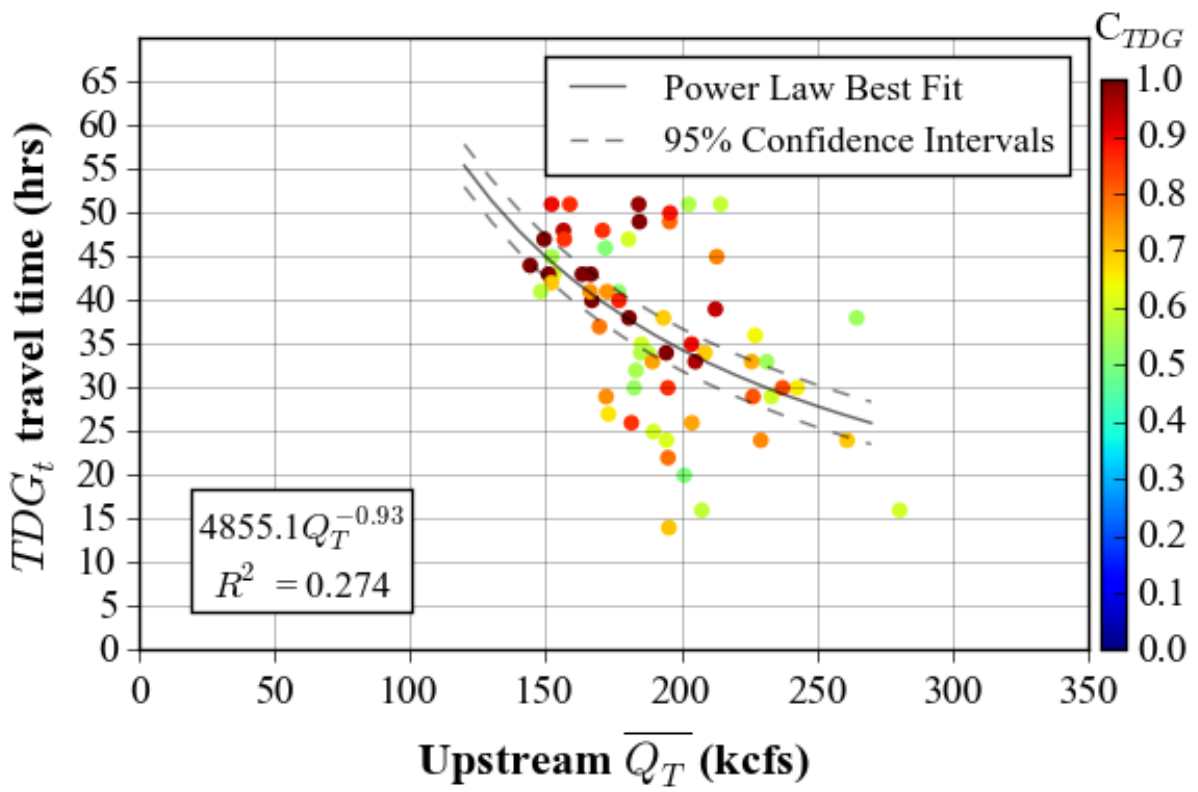

Figure 12 - Plot of relationship for tailrace TDG travel (lag) time between Grand Coulee and Chief Joseph as a function of mean upstream (Grand Coulee) powerhouse and spill flow. Scatter points are colored by the strength of the correlation at the given travel time $\left(C_{T D G}\right)$, and the best fit equation and $R^{2}$ are shown at the bottom left.

\subsubsection{FUTURE WORK FOR TDG TRANSFER}

Further refinement of the methodologies for the TDG transfer are required before being ready for implementation into RiverWare. CADSWES will need to review and verify the appropriateness of the formulation for the TDG lag time as a function of flow with respect to the linearization requirements for use in the optimization scheme in RiverWare.

Further refinement is also required for the methodology for predicting the magnitude of the transfer of the TDG. Figure 13 illustrates some preliminary results for TDG transfer prediction from Wanapum to Priest Rapids for flow classification and no flow classification. The preliminary results indicate some consistent overprediction with scatter. Suggestions from CADWES indicate the predictive methodology could benefit from further refinements to how the relationships between upstream and downstream TDG values may be improved. In addition, CADSWES have recommended improvements to the predictive formulation variables that would be compatible with the linearization requirements for use in the optimization scheme in RiverWare. 


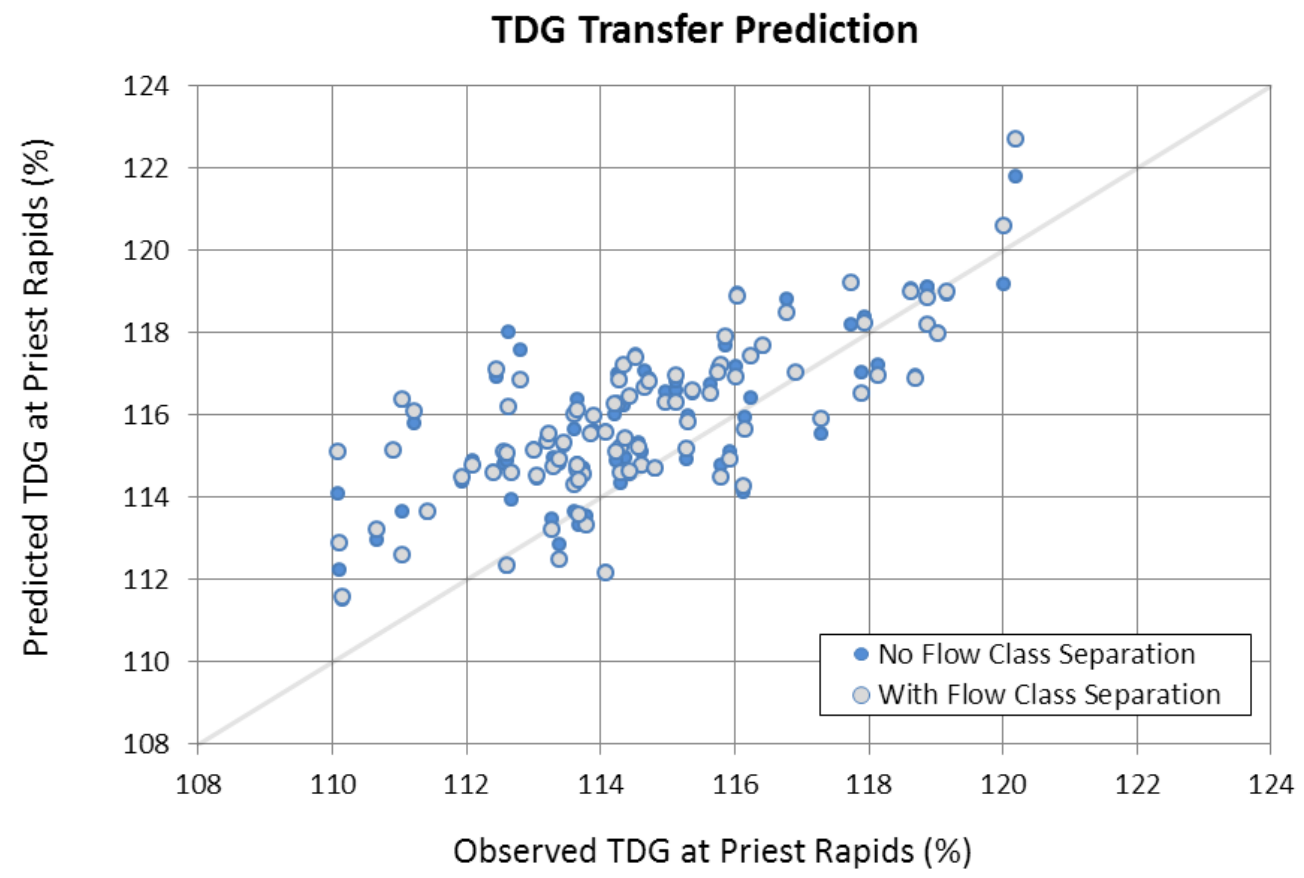

Figure 13 - Preliminary results plot of TDG transfer magnitude prediction between Wanapum and Priest Rapids. The results are presented for two different cases - one based on no flow class separation and one using flow class separation. For the no flow class separation, only one predictive equation, independent of flow is used. For the flow class separation, 5 separate equations each pertaining to different ranges of flow are used to estimate reservoir TDG levels. Predictive performance for the two approaches are almost identical exhibiting a slight tendency for over predicting TDG levels. 


\section{CUMBERLAND RIVER SYSTEM}

Identified in Figure 14 are the two projects of interest for the Cumberland River project : Cordell Hull and Old Hickory. These projects are located downstream of Wolf Creek Dam. Dale Hollow and Center Hill feed into the reservoirs of Cordell Hull and Old Hickory respectively. Both Cordell Hull and Old Hickory sites serve purposes of navigation, hydropower, and some recreation. Cordell Hull contains 3 hydropower turbine units that provide an annual output of 250 million kilowatt hours of power (USACE 2013a) and Old Hickory contains 4 hydropower turbine units that provide an annual output of 420 million kilowatt hours of power (USACE 2013b).

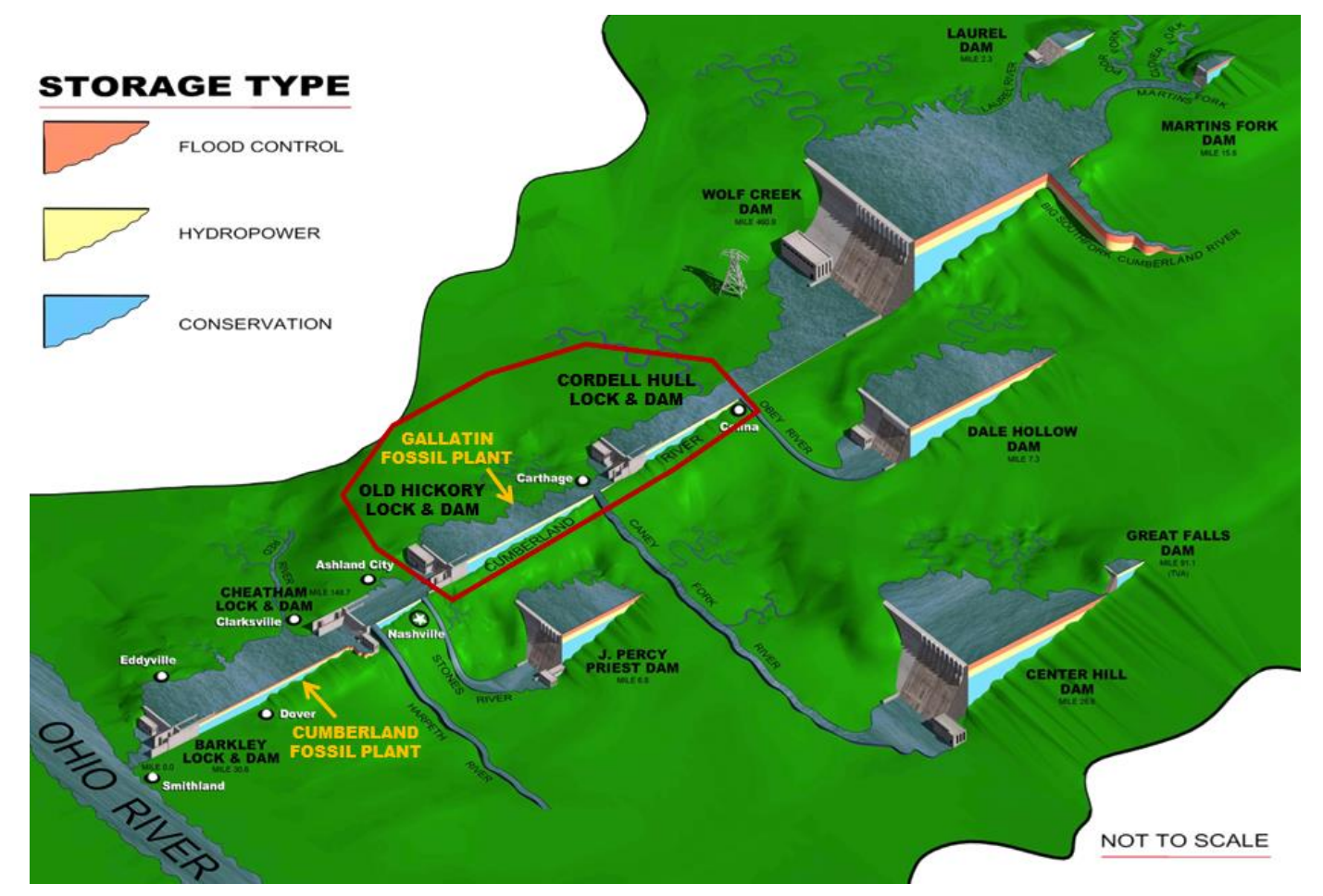

Figure 14 - Projects along the Cumberland River (courtesy of USACE Nashville District). Of interest to the current project are the Cordell Hull and Old Hickory reservoirs circled in the figure.

\subsection{DECISION SUPPORT SYSTEM DEVELOPMENT}

Collaborative efforts between ORNL, Vanderbilt University, and Lipscomb University have yielded a decision support system used to optimize hydropower generation based on environmental constraints for a two-reservoir system on the Cumberland River. Work was performed in close collaboration with the Nashville District of the U.S. Army Corps of Engineers. 


\subsubsection{OVERVIEW}

Accompanied with the need for increased and improved hydropower generation is the concern for behaviors and effects of environmental water quality issues. The extensive dependency of temperature, dissolved oxygen, sediment, and greenhouse gas emissions with that of hydropower and reservoir operations requires a sophisticated approach for predicting and optimizing such a multi-constraint system aimed to improve hydropower generation, water use, and environmental stewardship within the context of a forecasting and dispatch system. Doing so requires an innovative approach for enabling the reduction of computational resources and overhead associated with obtaining high fidelity modeling results yet being able to still fully utilize and take advantage of such results to effectively and comprehensively optimize a hydropower system.

\subsubsection{METHODOLOGY}

The methodology, as illustrated in Figure 15, in this research effort involves the reduction of high-fidelity water quality model results into a comprehensive and accessible surrogate model framework that can be used to optimize a complex, environmentally constrained hydropower system. This is accomplished with the development of a series of CE-QUAL W2 water quality model runs using a combinatory matrix of various input and initial conditions. The data management component of the approach facilitates automatic organization of the inputs and outputs and execution of the various runs. The models results containing the wide variety and comprehensiveness of possible simulation conditions are used to train a nonlinear autoregressive network with exogenous inputs (NARX) neural network model for discharge temperature and dissolved oxygen. Once trained and validated, this model reduction component (from CE-QUAL W2 to the NARX) enables high-fidelity modeling quality results to be made and realized fairly quickly and reliably for a given set input and initial conditions situations without the requirement of extensive computational resources. Output from the NARX model is used for optimization of hydropower generation for environmental constraints of the system. 


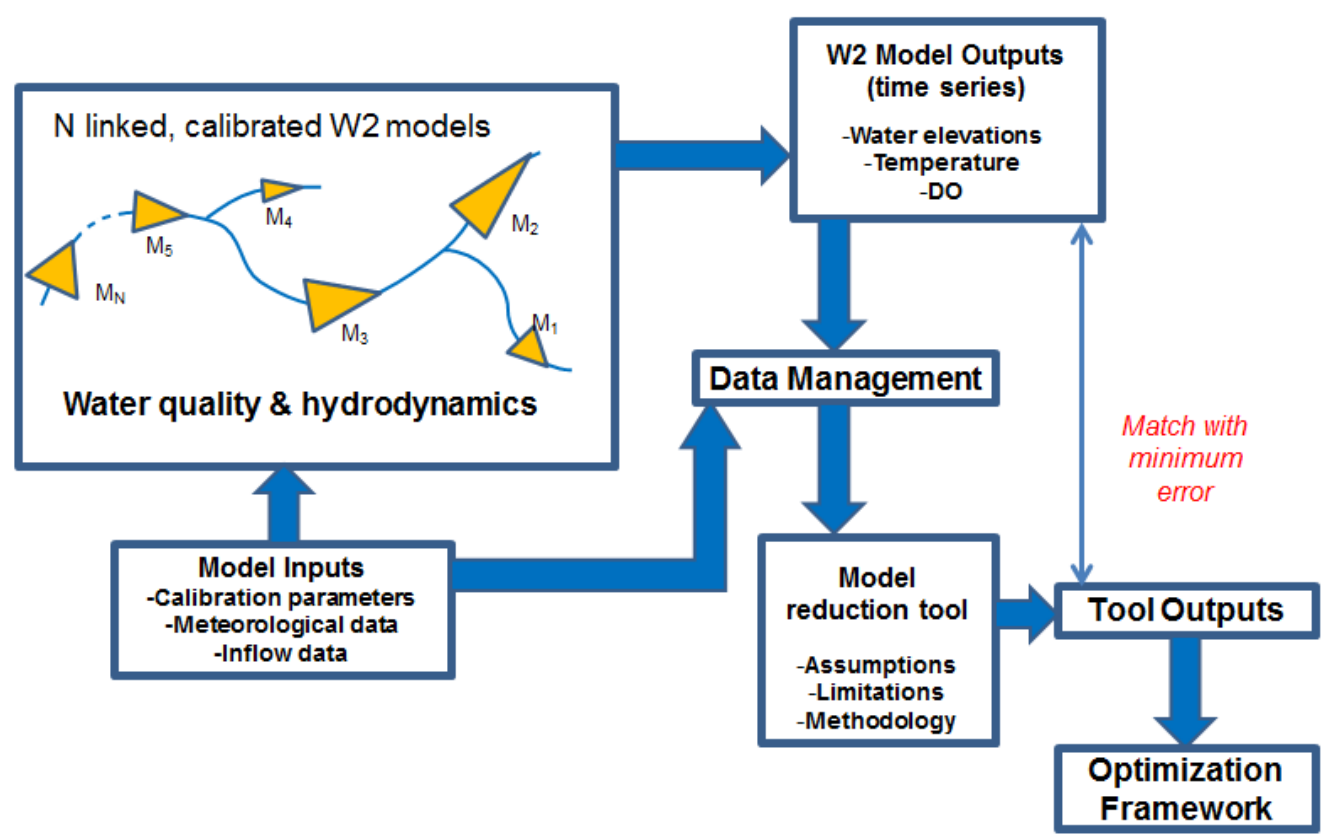

Figure 15 - Overall approach methodology for the decision-support system development illustrating the reduction of high-fidelity W2 model results into a useful input for use in optimization.

\subsection{IMPLEMENTATION OF DECISION SUPPORT SYSTEM}

The implementation of the decision support system involves an initial execution of a CE-QUAL W2 simulation to obtain base case results and conditions used to conduct optimization. Next, optimization is conducted using the CE-QUAL W2 water balance and water quality surrogate models. At last, a comparative CE-QUAL W2 simulation is run to check the performance of the model and results against the surrogate modeling results. If results are comparable, an optimal solution has been found. If not, the NARX undergoes additional training to include the computed purported optimum solution before subsequent optimization is performed again.

\subsubsection{CE-QUAL-W2}

CE-QUAL-W2 is a hydrodynamic and water quality model used for modeling reservoirs, rivers, lakes, etc. Figure 16 is a results plot of a simulation for inflow to Old Hickory reservoir. In general, results from several simulation runs were used to populate the training data set used for training the NARX for the Old Hickory and Cordell Hull sites. Incremental adjustments are made to flow, water temperature, and dissolved oxygen inputs to produce a varied and combinatory set of conditions for the years 2005 , 2006, and 2007. 


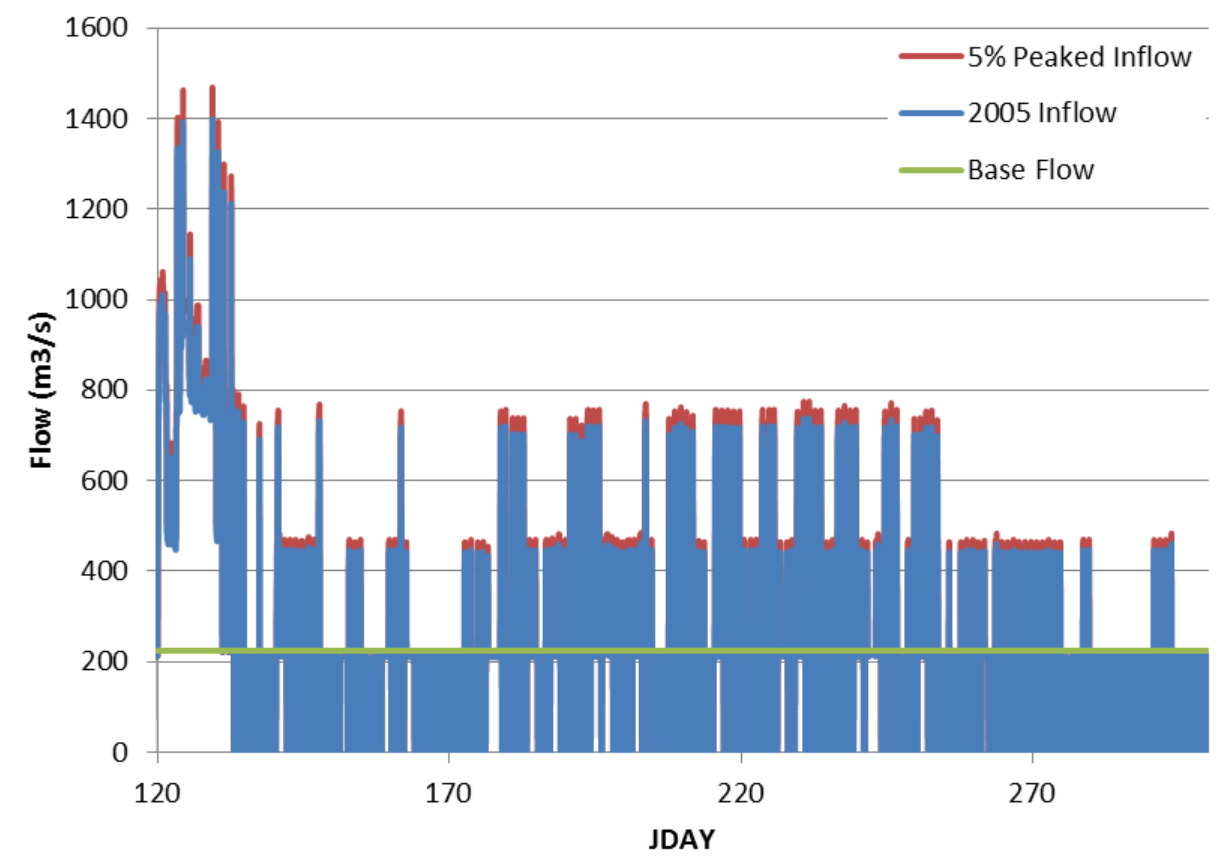

Figure 16 - CE-QUAL W2 example simulation results for Old Hickory flow used as training data sets for the neural network.

\subsubsection{NONLINEAR AUTOREGRESSIVE NETWORK (NARX) MODEL}

The nonlinear autoregressive neural network model utilizes the CE-QUAL W2 simulation results as training data to establish a model capable of predicting time-dependent behaviors based on a variety of external inputs. Several correlative tests were performed to determine the most influential external input parameters and respective input lag times. Based on this, inflow and water temperature defined at various locations within the model as well as air temperature, dew point, turbine and spill flow are identified as the most influential external inputs for maximizing model prediction performance. The most appropriate input lag times with respect to the system inputs were determined for discharge temperature prediction as well.

A total of $729 \mathrm{~W} 2$ model simulations were performed for each reservoir and the model results were randomly divided into approximately $70 \%$ for training, $15 \%$ for validation, and $15 \%$ for testing of the neural network. A systematic approach for assessing the performance of the NARX model for each of the predictors for flow, temperature, and dissolved oxygen was made and incorporated into a defined final set of NARX models providing the best results as compared to validation cases. Figure 17 depicts the error distribution of predictive performance for temperature and dissolved oxygen in the training and validation sets for Old Hickory. Comparisons of the NARX model prediction performance with that of the W2 simulations are plotted in Figure 18 and Figure 19 for discharge temperature and dissolved oxygen respectively. 

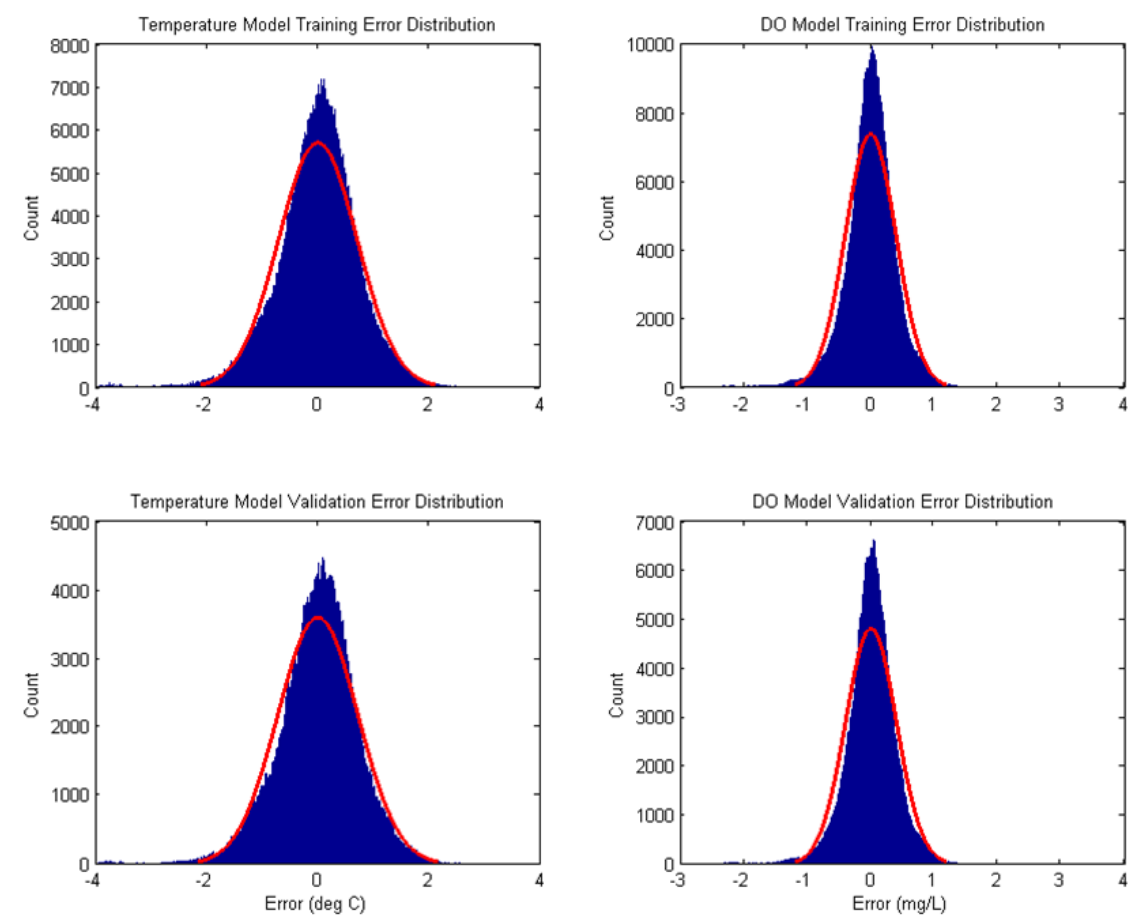

Figure 17 - Distribution of temperature and dissolved oxygen prediction errors for the training and validation data sets for Old Hickory. The training and validation have similar distributions indicating the neural network's predictive power.

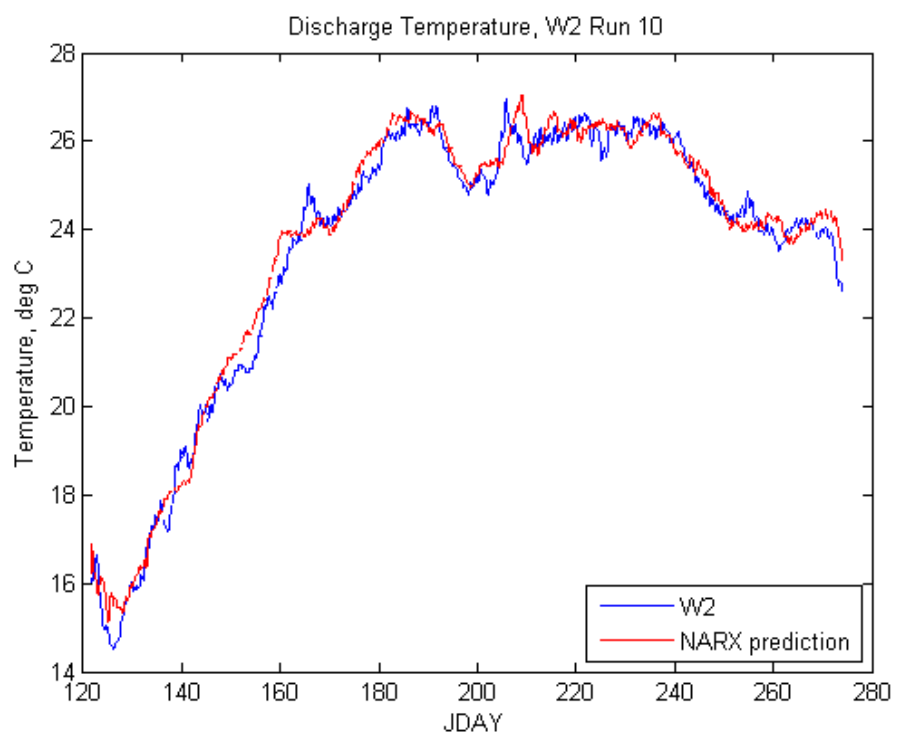

Figure 18 - Comparison of discharge temperature prediction from the NARX and W2 model results for Old Hickory. The comparison of the two plots indicate that the neural network's performance for prediction of temperature is very good. 


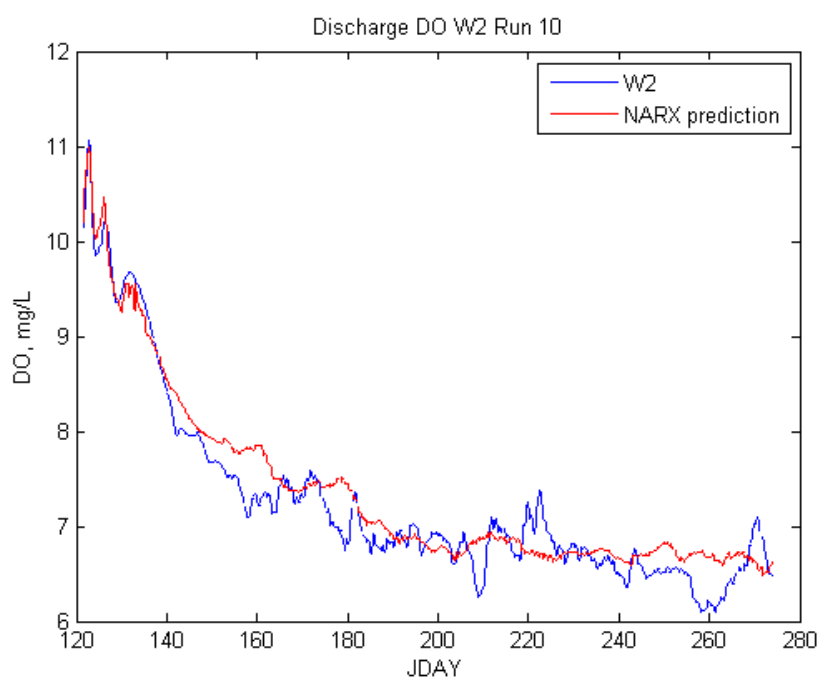

Figure 19 - Comparison of discharge dissolved oxygen prediction from the NARX and W2 model results for Old Hickory. . The comparison of the two plots indicate that the neural network's performance for prediction of dissolved oxygen is very good.

\subsection{DECISION SUPPORT SYSTEM OPTIMIZATION}

The objective of the decision support optimization is to maximize the generation value accompanied by five "hard" and two "soft" constraints. The five hard constraints are:

- Pool elevation maintained within power pool elevations.

- No generation periods should not exceed 6 hours.

- Discharge dissolved oxygen limit.

- Hourly limit on number of active units.

- Turbine release compatibility with number of active units

The soft constraints used for locating feasible solutions are:

- Penalization for deviations from target midnight elevations.

- Penalization for continuous switching of units off and on. 


\subsubsection{OLD HICKORY AND CORDELL HULL OPTIMIZATION RESULTS}

The optimization scheme is demonstrated for single reservoir optimization for old Hickory. The site's operations are optimized to maximize generation according to objective defined in 3.3 but with two additional constraints. The additional constraints are an upper limit on discharge temperature of 80.6 degrees Fahrenheit and a lower limit of reservoir water elevation to prevent the drainage of the reservoir beyond the ability to provide generation. The results of the optimization for Old Hickory for turbine flow, discharge temperature, and headwater elevation are depicted in Figure 20, Figure 21, and Figure 22 respectively.

It is observed that the optimal solution yields sharp spikes in turbine discharges (as compared to 2005 operations) offset by periods of lower discharge to increase generation. This results in not more than a tenth of foot deviation in reservoir elevation. In addition, discharge temperature is reduced for the majority of the time period.

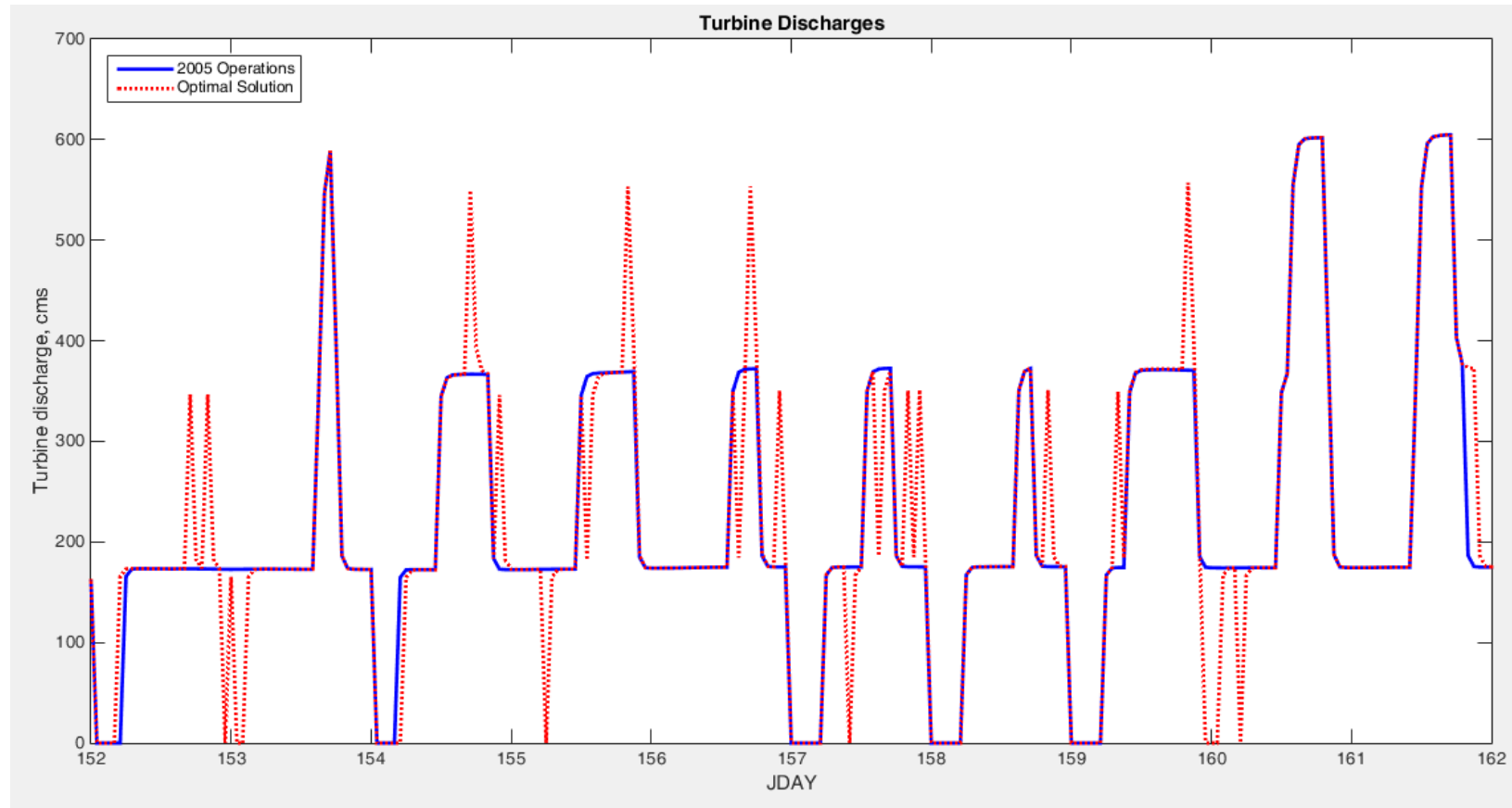

Figure 20 - Turbine discharge flow results for optimization of generation at Old Hickory. The optimal solution for the maximization of generation is characterized by spikes in turbine discharge in contrast to the 2005 operations that are indicative of longer periods of lower turbine discharge. 


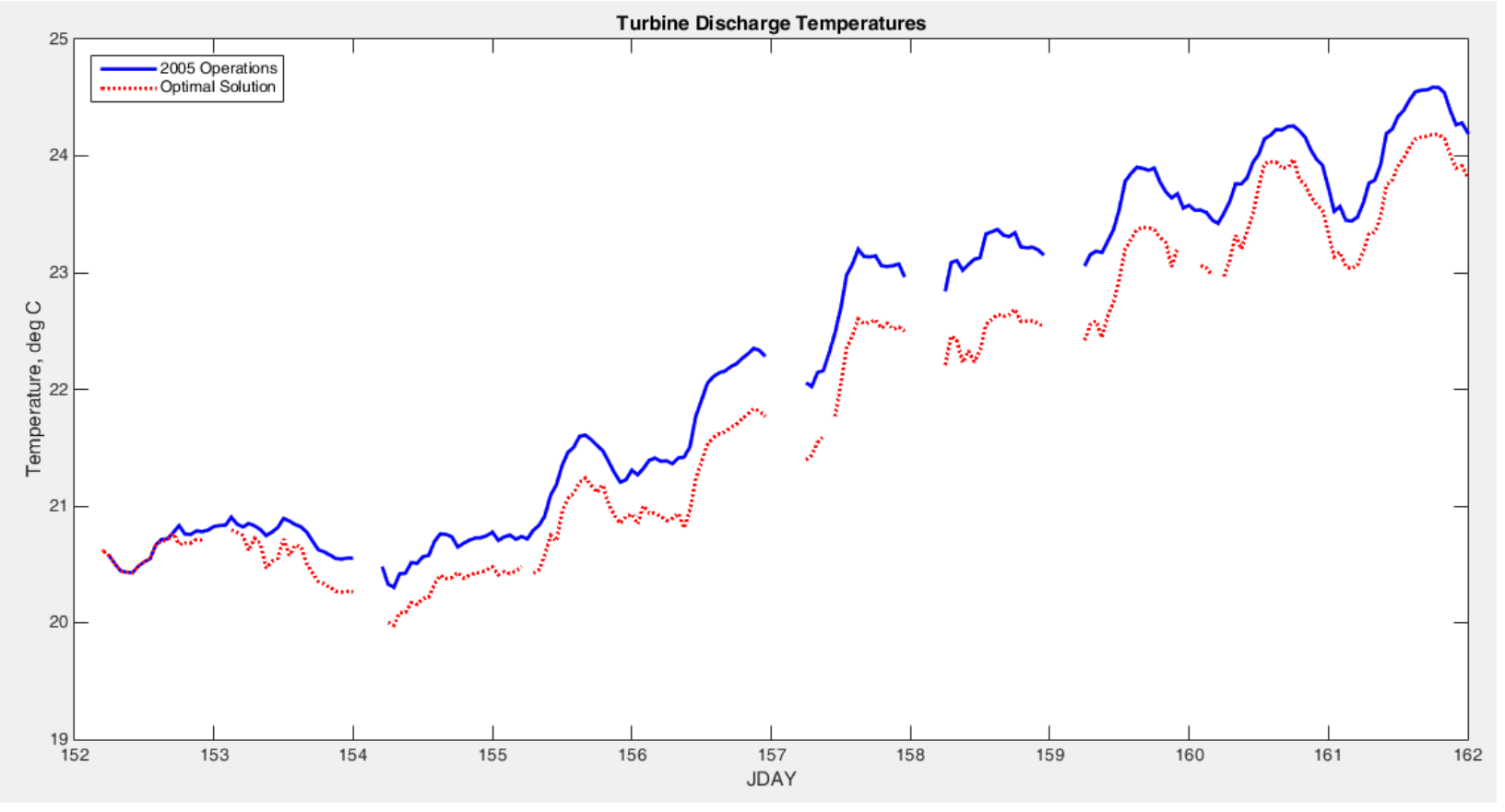

Figure 21 - Turbine discharge temperature results for optimization of generation at Old Hickory yields an overall lower discharge temperature. 


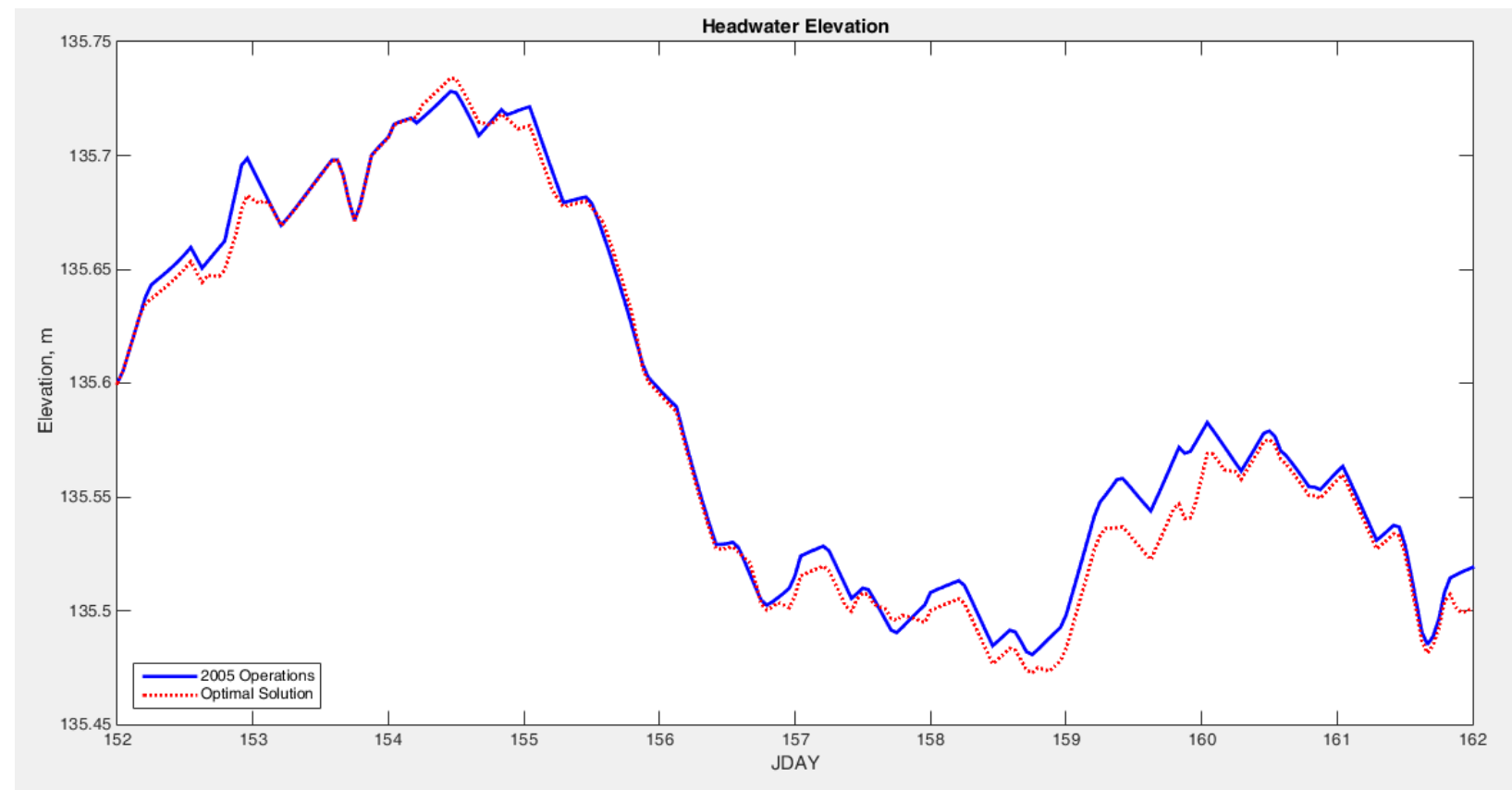

Figure 22 - Headwater elevation results for optimization of generation at Old Hickory did not change significantly from those associated with the 2005 operations.

\section{CONCLUSION}

The development, implementation, and optimization results of the two water quality projects for the MidColumbia River System and the Cumberland River are presented. Effort in each of the two projects have yielded new methodologies and tools for improving the role of integrated environmental assessment and water quality modeling within the context of enabling a holistic approach to hydropower system improvement and scheduling. Not only have novel tools for predicting environmental responses to hydropower operations been developed, but this effort has also enabled technology transfer to be accomplished. The TDG prediction methodology is incorporated into Riverware and made available to all users of the software. In addition, the state-of-the art modeling approach for reducing high-fidelity simulation to surrogate models for improved hydropower system forecasting on the Cumberland River is being improved to include all reservoirs in the system and is highly anticipated to be incorporated into the U.S. Army Corps of Engineer's suite of modeling tools used to forecast and manage the river system. 


\section{REFERENCES}

Stewart, K., Witt, A., and Hadjerioua, B. (2015). Total Dissolved Gas Prediction and Optimization In RIVERWARE, ORNL/TM-2015/551. Oak Ridge National Laboratory, Oak Ridge, TN.

USACE (2013a) U.S. Army Corps of Engineers, Nashville District. "Cordell Hull Dam." Retrieved April 29, 2013, from http://www.lrn.usace.army.mil/Locations/Dams/CordellHullDam.aspx.

USACE (2013b) U.S. Army Corps of Engineers, Nashville District. "Old Hickory Lake > Pertinent Data." Retrieved November 10, 2013, from http://www.lrn.usace.army.mil/Locations/Lakes/OldHickoryLake/PertinentData.aspx

Witt, A., Magee, T., Stewart, K., Hadjerioua, B., Neumann, D., Zagona, E., Politano, M. Development and implementation of an optimization model for hydropower and total dissolved gas in the midColumbia River System. Submitted to Journal of Water Resources Planning and Management, October 2016.

Zagona, E., Magee, T., and Clement, M. (2012), Optimization of Water and Power Objectives Using Riverware, BPA Hydro Modeling Conference, February 2012. 